A Parallel Formulation of Whorfian and Neo-Whorfian Linguistic Relativity

\author{
A Thesis \\ Presented to \\ The Division of Philosophy, Religion, Psychology, and Linguistics \\ Reed College
}

\author{
In Partial Fulfillment \\ of the Requirements for the Degree \\ Bachelor of Arts
}

Molly L. Lewis

May 2009 

Approved for the Division (Linguistics)

Stephen E.D. Hibbard 



\section{Table of Contents}

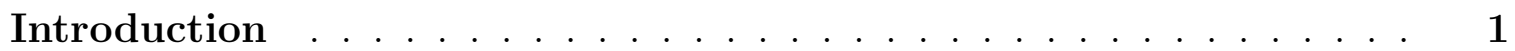

Chapter 1: Whorfian Linguistic Relativity . . . . . . . . . . . . 5

1.1 Linguistic Relativity at the Level of langue: Boas and Sapir . . . . . . 7

1.2 Linguistic Relativity at the Level of parole: Whorf . . . . . . . . . . 11

Chapter 2: Neo-Whorfian Linguistic Relativity . . . . . . . . . . . 25

2.1 Formal Semiotic Grounding . . . . . . . . . . . . . . 25

2.2 Neo-Whorfian Linguistic Relativity and Culture . . . . . . . . . 37

Chapter 3: A Reformulation of Whorfian Linguistic Relativity . . . . 47

3.1 Formal Semiotic Grounding: Reformulated . . . . . . . . . . . 47

3.1.1 Fashions of Speaking as Metaphorical Interpretations of Diagrammatic Classes . . . . . . . . . . . . . . . 47

3.1.2 Metaphorical Interpretations within Poetic Language: The Ana$\log$ to Metaphorical Interpretations of Grammatical Categories at the Level of Reference and Predication . . . . . . . . . . . 56

3.1.3 Fashions of Speaking and Poetic Metaphor . . . . . . . . . . 64

3.2 Whorfian Linguistic Relativity and Culture . . . . . . . . . . 66

Chapter 4: Conclusion . . . . . . . . . . . . . . . . 75

Bibliography ... . . . . . . . . . . . . . . . 77 



\section{List of Figures}

1.1 Syntagmatic and paradigmatic structuralist axes. . . . . . . . . . 12

1.2 Peircean sign relation. . . . . . . . . . . . . . . . . . . . 15

1.3 Peircean sign relation for $/$ cat $/ \ldots \ldots \ldots \ldots \ldots \ldots$

1.4 The sociohistorical diagrammatic reasoning process. . . . . . . . . 21

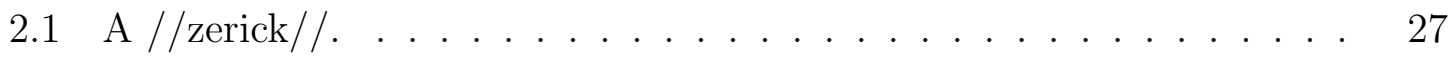

2.2 A parallel presentation of Whorfian and Neo-Whorfian theory. . . . . 32

2.3 A diagram of the relationship between Whorfian and Neo-Whorfian theories of linguistic relativity. . . . . . . . . . . . . . . . 33

2.4 Contrasting representation of the objects of relativity in Whorfian and Neo-Whorfian thought. . . . . . . . . . . . . . . . . 36

2.5 A representation of Silverstein's cultural concept. . . . . . . . . . 39

2.6 Silverstein's theory of culture as presented in "Cultural Concepts," and its relation to $n$-th order indexicality. . . . . . . . . . . . 44

3.1 A realist representation of reality . . . . . . . . . . . . 49

3.2 Language as a system of organizing reality . . . . . . . . 50

3.3 A representation of the implicit role of metaphor within the sociohistorical diagrammatic reasoning process . . . . . . . . . . 53

3.4 A comparative representation of Quinn's theory of metaphor and that of cognitive linguists . . . . . . . . . . . . . . . . . 69

4.1 Argument overview . . . . . . . . . . . . . 76 



\section{Notation Conventions}

\begin{tabular}{ll}
\hline Notation & Denotation \\
\hline /example/ & Representamen (Thirdness), Type, Legisign \\
//example// & Object (Thirdness) \\
[example] & Representamen (Secondness), Token, Sinsign \\
[[example]] & Object (Secondness) \\
<example> & Interpretant, Idea \\
lexample] & Quality (Firstness), Qualisign \\
example & Linguistic sign \\
'example' & Orthographic representation of a linguistic sign \\
"example" & Quotation \\
ExAmPLE & Technical term \\
\hline
\end{tabular}





\section{Abstract}

The claim of linguistic relativity, broadly, contains two components: (i) languages differ in the way they divide the world into meaningful units, and (ii) the way a language divides the world into meaningful units influences habitual thought. The conjunction of these two components yields the central claim of linguistic relativity: Speakers of different languages live in different habitual thought worlds. Theorists have addressed linguistic relativity in two different domains of linguistic meaning: symbolic and indexical. Roughly, these two domains can be understood as contextindependent and context-dependent meaning, respectively. Benjamin Lee Whorf is the central figure in the symbolic domain of linguistic relativity ("Whorfian linguistic relativity"). Michael Silverstein is responsible for the extension of linguistic relativity into the indexical domain ("Neo-Whorfian linguistic relativity"). While theoretically parallel, the two theories are framed in terms that mask their underlying commonality. The present project is thus to formulate both theories within a single coherent framework. I present a framework that rests on a semiotic principle proposed by Silverstein in the Neo-Whorfian domain: The principle of unavoidable referentiality. This principle states that speakers will be less susceptible to the 'thought grooves' of their language when the form of the meaning at issue coincides with a form with denotational value. By framing linguistic relativity in the symbolic realm in terms of metaphor, I argue that the principle of unavoidable referentiality can be applied to Whorfian theory. A formulation of the two theories within a common framework highlights their inter-relationship and, ultimately, allows both to be situated within a single theory of culture. 

To my parents, Bonnie and Marshall, for giving me such a rich beginning, and so many possibilities. 



\section{Introduction}

For theorists in the tradition of anthropological linguistics, language exists at the level of sociocultural interaction. That is, language is not an abstract entity in the mind-brains of speakers, or merely a set of structural facts, but rather unavoidably situated within the context of speakers in a culture. From the view that culture is, fundamentally, a way of organizing the world, a treatment of language from this perspective inevitably leads to a consideration of how language relates to thought. In the broadest of terms, theorists of linguistic relativity argue this relationship to be one of constraint: language guides habitual, everyday thought. In conjunction with the assumption that languages differ in fundamental ways, this claim becomes one of cultural relativity. The claim of linguistic relativity can thus be represented as: Languages differ in the way that meaning is parceled out into form and this difference has consequences for habitual cognitive tendencies.

Theorists have approached this claim from two different semiotic aspects of language: SYMBOLIC ${ }^{1}$ and INDEXICAL ${ }^{2}$. Each of these aspects concerns a different way in which language means. Symbolic meaning is the meaning most often associated with language: it embodies the notion that language is about categorizing things in the world. Thus, for example, the symbolic meaning of the word cat is, roughly, the concept of the four-legged furry animal with whiskers and paws. In contrast,

\footnotetext{
${ }^{1}$ Symbols "represent their objects, independently alike of any resemblance or any real connection, because dispositions or factitious habits of their interpreters insure their being so understood" (Peirce, Commens, EP 2:460-461). [EP x:y refers to The Essential Peirce, where ' $\mathrm{x}$ ' indicates the volume number and ' $y$ ' indicates the paragraph number.]

${ }^{2}$ Indexes "represent their objects independently of any resemblance to them, only by virtue of real connections with them" (Peirce, Commens, EP 2:460-461).
} 
indexical meaning in language is the type of meaning necessarily informed by context and associated with cultural knowledge. This type of meaning is exemplified by the statement [My, it is cold in here], uttered by a guest sitting in a house with an open window. The host might interpret this utterance to mean that the guest would like the window to be closed, and act accordingly. This is an interpretation of indexical meaning, or as it is often referred to in disciplinary linguistics, PRAGMATIC ${ }^{3}$ meaning. Thus, in the domain of symbolic meaning, the claim of linguistic relativity takes the form: Languages differ in the way that symbolic meaning is parceled out into form, and this difference has consequences for cognitive tendencies in the symbolic realm of thought. In the indexical domain, the claim of linguistic relativity takes the form: Languages differ in the way that indexical meaning is parceled out into form, and this difference has consequences for cognitive tendencies in the indexical realm of thought.

Benjamin Lee Whorf is most closely identified with claims of linguistic relativity in the symbolic domain, and Michael Silverstein is most closely identified with claims in the indexical domain. Whorf's central claim is that language and thought are related at the level of habit. He argues that the way speakers habitually talk affects the way they habitually think. This claim becomes significant when it is considered in conjunction with the central tenet of structuralist thought: ${ }^{4}$ languages have fundamentally different structures. That is, languages, constituted by units of symbolic meaning, are analyzed as systems which are fundamentally different. Together, these two claims lead to the conclusion that there is relativity in thought. That is, because languages are structured in different ways, speakers of different languages conceptualize the world in different ways; they have different symbolic knowledge. This

\footnotetext{
${ }^{3}$ The study of "usage as discourse in actual situations of communication, looking for regularities of how 'appropriate' linguistic forms occur as indexes (pointers to) the particularities of an intersubjective communicative context and how 'effective' linguistic forms occur as indexes of (pointers to) intersubjective consequences of communication" (Silverstein, Language and the Culture of Gender 222).

${ }^{4}$ STRUCTURAL LINGUISTICS: "Any school or theory in which language is conceived as a selfcontained, self-regulating system, whose elements are defined by their relationship to other elements" (Matthews, Concise Oxford).
} 
conclusion emerges from the claims of Whorf's intellectual predecessors, particularly Franz Boas, Edward Sapir, and Ferdinand de Saussure. Following Whorf, Silverstein applies the Whorfian claim of linguistic relativity in the symbolic domain to the indexical domain, and thus establishes the distinct field of Neo-Whorfian thought. Silverstein argues that speakers of different languages not only have different symbolic knowledge, but that they also have different indexical knowledge. Thus, based on the premise that languages differ in the way symbolic and indexical meanings are parceled out into linguistic form, theorists of linguistic relativity argue that speakers of different languages differ cognitively, both at the level of symbolic meaning and at the level of indexical meaning.

At an abstract level, the commonality between Whorfian and Neo-Whorfian linguistic relativity is thus clear: speakers of different languages differ in their habitual cognitive tendencies. At a more nuanced level, however, the commonality is less evident. That is, the arguments by which language is claimed to produce cognitive differences in its speakers differ radically between the two domains. In the symbolic domain, Whorf centers his claim of relativity around the notion that speakers of different languages tend to talk about abstract concepts, such as time, in different ways. In Whorf's terms, that is, speakers of different languages use different FASHIONS OF SPEAKING. Silverstein, in contrast, centers his claim of relativity in the indexical realm in terms of AWARENESS OF INDEXICAL MEANING. He argues that speakers' awareness of indexical meaning in language is predictable based on a set of semiotic principles. The notions of fashions of speaking and awareness of indexical meaning have little self-evident similarity.

Though Whorfian and Neo-Whorfian claims are presented in different terms, I argue that the theory at issue is not different. I suggest that the shared theory can be made less opaque by framing Whorfian linguistic relativity with respect to the terms of Neo-Whorfian linguistic relativity. Specifically, that is, by framing Whorfian linguistic 
relativity in terms of Silverstein's principle of unavoidable referentiality. Silverstein's principle of unavoidable referentiality states, roughly, that speakers tend to be aware of indexical meaning in language when the meaning 'rides on' a form with denotational value. I argue that Whorfian theory can be framed in terms of this principle by formulating it as Peircean metaphor. The formulation of Whorfian and Neo-Whorfian linguistic relativity within a common framework allows both to be situated with respect to a common theory of culture. I argue that each theory corresponds to a different element within the theory of culture presented by Silverstein. The situation of the two theories within a common theory of culture exemplifies the value in the proposed common framework for the two theories.

Chapter I presents Whorfian linguistic relativity in its historical context. I argue that Franz Boas and Edward Sapir laid the groundwork for Whorf with claims of relativity in language structure. I then present Whorf's argument, in conjunction with Silverstein's interpretation, about how relativity at the level of language structure produces relativity at the level of actually occurring utterances. Chapter II outlines Silverstein's theory of Neo-Whorfian linguistic relativity and its relationship to his theory of culture. Chapter III, broadly, seeks to reformulate Chapter I in terms of Chapter II. I suggest that Whorfian theory can be conceived of as a claim about awareness of metaphorical interpretations. The conceptualization of Whorfian theory as metaphor allows the theory to be stated in Neo-Whorfian terms. Finally, I suggest how Whorfian theory is related to Silverstein's theory of culture presented in Chapter II. 


\section{Chapter 1}

\section{Whorfian Linguistic Relativity}

The distinct contributions of Boas, Sapir and Whorf to the theory of linguistic relativity can be understood by considering Saussure's distinction of language at two different ontological levels: $\mathrm{TOKEN}^{1}$ and $\mathrm{TYPE}^{2}$. At the level of tokens are actual existing things in the world, the word [thesis] printed on the second line of the title page, for example. For Peirce, this is the level of SECONDNEss ${ }^{3}$. In language, Saussure refers to this ontological realm as PAROLE ${ }^{4}$. Language at the level of parole is

\footnotetext{
1 "A Single event which happens once and whose identity is limited to that one happening or a Single object or thing which is in some single place at any one instant of time, such event or thing being significant only as occurring just when and where it does, such as this or that word on a single line of a single page of a single copy of a book, I will venture to call a Token" (Peirce, Commens, CP 4.537). [CP x.y refers to The Collected Papers of Charles Sanders Peirce, where 'x' indicates the volume number and ' $\mathrm{y}$ ' indicates the paragraph number.]

2 "a definitely significant Form, I propose to term a Type. [... In order that a Type may be used, it has to be embodied in a Token which shall be a sign of the Type, and thereby of the object the Type signifies. I propose to call such a Token of a Type an Instance of the Type" (Peirce, Commens, CP 4.537).

3 "Let us begin with considering actuality, and try to make out just what it consists in. If I ask you what the actuality of an event consists in, you will tell me that it consists in its happening then and there. The specifications then and there involve all its relations to other existents. The actuality of the event seems to lie in its relations to the universe of existents. A court may issue injunctions and judgment against me and I not care a snap of my finger for them. I may think them idle vapor. But when I feel the sheriff's hand on my shoulder, I shall begin to have a sense of actuality. Actuality is something brute. There is no reason in it. I instance putting your shoulder against a door and trying to force it open against an unseen, silent, and unknown resistance. We have a two-sided consciousness of effort and resistance, which seems to me to come tolerably near to a pure sense of actuality. On the whole, I think we have here a mode of being of one thing which consists in how a second object is. I call that Secondness" (Peirce, Commens, CP 1.24).

4 "the act of speaking in actual situations by an individual" (Crystal, Ency. Dictionary 221)
} 
actual utterances of speech, the guest's statement [My, its cold in here], for example. Because parole exists in the existential realm, language at the level of tokens is recordable, and therefore amenable to analysis directly. The ontological realm of type, in contrast, exists at the level of abstract concepts. This level is what Peirce refers to as ThIRDnEss ${ }^{5}$. Types exist only in so far as they are instantiated in tokens (of themselves). Thus, the word [thesis] printed on the title page is a token of the type /thesis/, an abstract concept of a $<$ thesis $>$. Saussure refers to the ontological realm of type in language as $\mathrm{LANGUE}^{6}$. In this realm, language exists as a "language system," or "linguistic structure" (Saussure 14). That is, langue is a "grammatical system" that "each member of a community has learned" but "exists over and above the individual act of communication and the individual communicator" (Matthews, Short History 12). Crucially, langue, as a type-level phenomenon, exists only through its instantiation in actual speech utterances, Saussure's parole. Thus, framed in terms of the distinction between langue and parole, Chapter I presents Whorfian linguistic relativity in its historical context. I argue that the primary contributions of Boas and Sapir to the theory of Whorfian linguistic relativity, are at the level of langue. Whorf's contribution, in contrast, is in the extension of the theory of linguistic relativity from the ontological realm of langue to that of parole. Furthermore, I argue that Whorfian linguistic relativity may be seen as the explicit formulation of the implications inherent in Saussurean structuralism.

\footnotetext{
5 "The third is thought in its role as governing Secondness. It brings the information into the mind, or determines the idea and gives it body. It is informing thought, or cognition. But take away the psychological or accidental human element, and in this genuine Thirdness we see the operation of a sign" (Peirce, Commens, CP 1.536-537).; "Category the Third is the Idea of that which is such as it is as being a Third, or Medium, between a Second and its First. That is to say, it is Representation as an element of the Phenomenon" (Peirce, Commens, CP 5.66).

6 "It is both a social product of the faculty of speech and a collection of necessary conventions that have been adopted by a social body to permit individuals to exercise that faculty" (Saussure $9)$.
} 


\subsection{Linguistic Relativity at the Level of langue: Boas and Sapir}

Franz Boas, the first to present a clear formulation of linguistic relativity, describes languages as classification systems of experience that are motivated by the interests of speakers. Boas reasons that "since the total range of personal experience which language serves is infinitely varied [...], it is obvious that an extended classification system must underlie all articulate speech" (Boas 24). If this were not the case, suggests Boas, then "an infinitely large number of distinct phonetic groups would be required for expression" of an "infinitely large number of ideas" (25). According to Boas, the way a culture chooses to classify the world "depend[s] upon the chief interests of the people" (26). Thus, because interests vary across cultures, so too do languages. Importantly, however, Boas argues that "each language, from the point of view of another language, may be arbitrary in its classifications" (26). That is, each system of classification is unmotivated, or arbitrary, from an analytic perspective. This argument allows for an underlying equality in Boas' theory: Although languages differ in their systems of classification, "all languages are equally viable vehicles for the expression of thought" (Foley 195). The underlying equality which this argument affords, it should be noted, was central to Boas' larger project: "dismantling the proposed racial hierarchy that was so prevalent in both popular and academic circles in the early twentieth century" (Paulsen 9). Thus, the core claim of the Boasian theory of linguistic relativity, that each language is a different classification system, is a claim of relativity at the level of langue.

In his presentation of linguistic relativity, Boas makes it clear that languages are fundamentally different but nonetheless equal. That is, that languages have fundamentally different structures, but that each structure is equally (un)motivated. What Boas fails to make explicit are the consequences of this theory: So what that lan- 
guages differ at the level of langue? The potential to make the consequences of his theory explicit, I argue, lies in a structural interpretation of his claims. Boas did not, however, formulate his claims in structural terms - that was Edward Sapir's contribution. Most significantly, Sapir introduced the notion of Saussurean value. It was from Sapir's interpretation of Boas from a structural perspective that the consequence of Boasian thought emerged: languages are incommensurable systems.

Sapir's contribution was thus the formulation of Boas claim of linguistic relativity in an explicitly structuralist framework. Sapir demonstrates that Boas' conception of languages as, one, different, but, two, equal is a consequence of two of the central tenets of structuralism: languages as autonomous systems and the principle of arbitrariness. Saussure conceived of language as "a system that has its own arrangement" (Saussure 22). Matthews explains this to mean that "a language is not a "nomenclature" or an "inventory [...] of individual components" but rather, a set of entities that exist "only through the association with one of the other" (Short History 18, 5). Saussure's chess analogy further illustrates this notion: a language conceived of as a system has parts external and internal to it just as a chess game has rules and locations of the pieces, which are internal, and the location of the board, which are external. What is relevant to language, just as to chess, are the internal parts; the nature of the 'rules,' the grammar, and how the 'pieces' are arranged. Such a consideration of the interrelations in the language system reflects what Saussure calls a SYNCHRONIC ${ }^{7}$ perspective. A synchronic perspective addresses the interrelations of the languages system at a particular point in time. A DIACHRONIC ${ }^{8}$ perspective, in contrast, considers the system as it changes through time. To illustrate this distinction, Matthews presents the example of foot in English: /foot/ is synchronically

\footnotetext{
7 "A linguistic phenomenon is said to be synchronic when all the elements and factors that it brings into play belong to one and the same moment of one and the same language (that is, to a single language state)" (Ducrot and Todorov 137).

8 "[A linguistic phenomenon] is diachronic when it brings into play elements and factors belonging to different states of development of a single language" (Ducrot and Todorov 137).
} 
related within the system to the plural form /feet/, but is diachronically related to the old English form /fōt/ (15). Boas' concern with language as an "extended classifications system" reflects a synchronic perspective on language.

The second central concept in structuralism is the principle of arbitrariness. Saussure's theory of the linguistic sign contains two components: the SIGNIFIER and the SIGNIFIED". The signifier is the "sound pattern" or the word form (at the type level), and the signified represents a concept (Saussure 66). Thus, in Saussurean terms, the word desk is in a signifier-signified relationship with the concept $<$ desk $>$. Crucially, Saussure argues that "the link between the signal and the signification is arbitrary." That is, that there is no external motivation for a given concept being represented by a particular word. Thus, the concept $<$ desk $>$ could be signified in theory by the signifiers /cat/ or /gato/ to the same effect as the signifier/desk/. For this reason, this principle ensures that there will be difference in the way languages cut up the world into signified chunks. But, it also ensures that they will be equally different: because no system is more motivated than another, that all systems are equally (analytically) unmotivated. Boas is consequently able to argue that, although languages are incommensurable systems, there is a "unity of fundamental psychological processes" among humankind (Boas 71). Thus, although Boas does not present linguistic relativity from within a structural framework, his theory reflects the central tenets of structuralism: a synchronic perspective on language and the principle of arbitrariness. Sapir identified these structural underpinnings and reformulated the theory to highlight these features.

Sapir's reformulation of Boasian thought in structural terms yielded a fresh perspective on linguistic relativity. The structural framework made available a whole set of theoretical tools, most significant of which, is the notion of Saussurean value. For

\footnotetext{
9 "For the Cours, the signifier is an 'acoustic image' in the minds of speakers; what it signifies is a 'concept' that [...] is triggered by it. But the 'linguistic sign' as such encompasses both. It is a 'mental entity with two sides': one a 'signifiant' or 'signifier,' and the other a 'signifié' or what is 'signified'" (Matthews, Short History 17).
} 
Saussure, "the values of words are their meanings" (Matthews, Short History 16). Values, or meanings, are determined negatively - that is, with respect to everything else in the system. Saussure states that "in language there are only differences without positive terms" (120). That is, meaning in language is determined with respect to everything else in the system. Consequently, meaning is emergent. Thus, because "each language has its own scheme," it follows from the Saussurean notion of value that languages are incommensurable (Sapir 119). That is, each language is a system, and because the identity of every part of the system depends on every other part, if one part of a language differs ever so slightly from another, the whole system fundamentally differs. A structuralist perspective thus functions to highlight the 'relative' in linguistic relativity; to highlight the extreme extent to which languages differ. Saussure's structuralism therefore contributes to the tradition of linguistic relativity not in providing content to the theory, but by providing the theoretical machinery necessary to consider the consequences of the theory.

Linguistic relativity, however formulated, is fundamentally the product of a structural perspective on language. Two structural notions are at its core: language as an autonomous system and the principle of arbitrariness. Independent of the tradition of linguistic relativity, Saussure developed structuralism as a fully-fledged framework within which to analyze language. By adopting a structural perspective, Sapir adopted the whole system and its consequences. That is, the formulation of linguistic relativism in structural terms made available a new set of theoretical machinery, and it is from this theoretical machinery that the consequences of linguistic relativity emerged. Namely, structuralism provided the notion of value, or meaning, as emergent from the system; as negatively defined. This realization leads inevitably to the conclusion that languages at the ontological level of langue are systems of meaning that are not just different, but different to the extent that they are incommensurable. 


\subsection{Linguistic Relativity at the Level of parole: Whorf}

By restricting their attention to the domain of langue, Boas and Sapir fail to consider language at the level which anthropological linguistics maintains should be the object of study: language at the level of actually occurring utterances, that is, at the level of parole. Without a consideration of relativity at the level of parole, a claim of relativity at the level of langue is of little consequence. A claim of relativity at the level of langue merely amounts to saying that speakers of different languages are working within different systems. This is analogous to the observation that the U.S. and France use different systems of measurement, imperial and metric. Crucially, this difference in systems holds no implication for a difference in what is measured: The two systems can be translated between by employing a simple equation, 1 yard $=.9144$ meters, for example. Similarly, two languages can, in principle, be translated between by a metalanguage. Whorf's contribution is thus to elaborate on the incomplete theory of linguistic relativity proposed by Boas and Sapir. Whorf provides a clear explanation of the link between language and thought by relating a claim of relativity at the level of langue to one at the level of parole.

To this end, Whorf first elaborates on the nature of the grammatical categories posited by Boas and Sapir. Grammatical categories are defined with respect to the SYNTAGMATIC $^{10}$ and PARADIGMATIC ${ }^{11}$ axes in the structuralist tradition. With reference to language, the syntagmatic axis may be represented as a horizontal axis and the paradigmatic axis as a vertical axis. These two axes are illustrated in Fig. 1.1 with the sentence, /The cat chases the mouse/. The paradigmatic axis is the axis of substitution. Along this axis are bits of language that are substitutable for each other. Thus, rather than/The cat chases the mouse/ the sentence below could read/The

\footnotetext{
${ }^{10}$ The axis of "the sequential relationships between the constituents at a give level of analysis" (Crystal, Ency. Dictionary 379).

${ }^{11}$ The axis of "the set of substitutional relationships a linguistic unit has with other units in a particular context; for example, in the context '- will leave,' the pronouns I, you, we, etc. can substitute for each other, and thus compromise a paradigm" (Crystal, Ency. Dictionary 286).
} 
gorilla chases the mouse/ or /The carrot chases the mouse/, or /The book chases the mouse/. Though perhaps a bit anomalous, each of these substitutions for /cat/ yields a grammatical sentence. The syntagmatic axis, in contrast, is the axis of concatenation. In the sentence below, the syntagmatic axis is defined by linear relations within the sentence: for example, /cat/ is preceded by the word /the/ and followed by the word /chases/. Note that, although the figure illustrates the structuralist axes

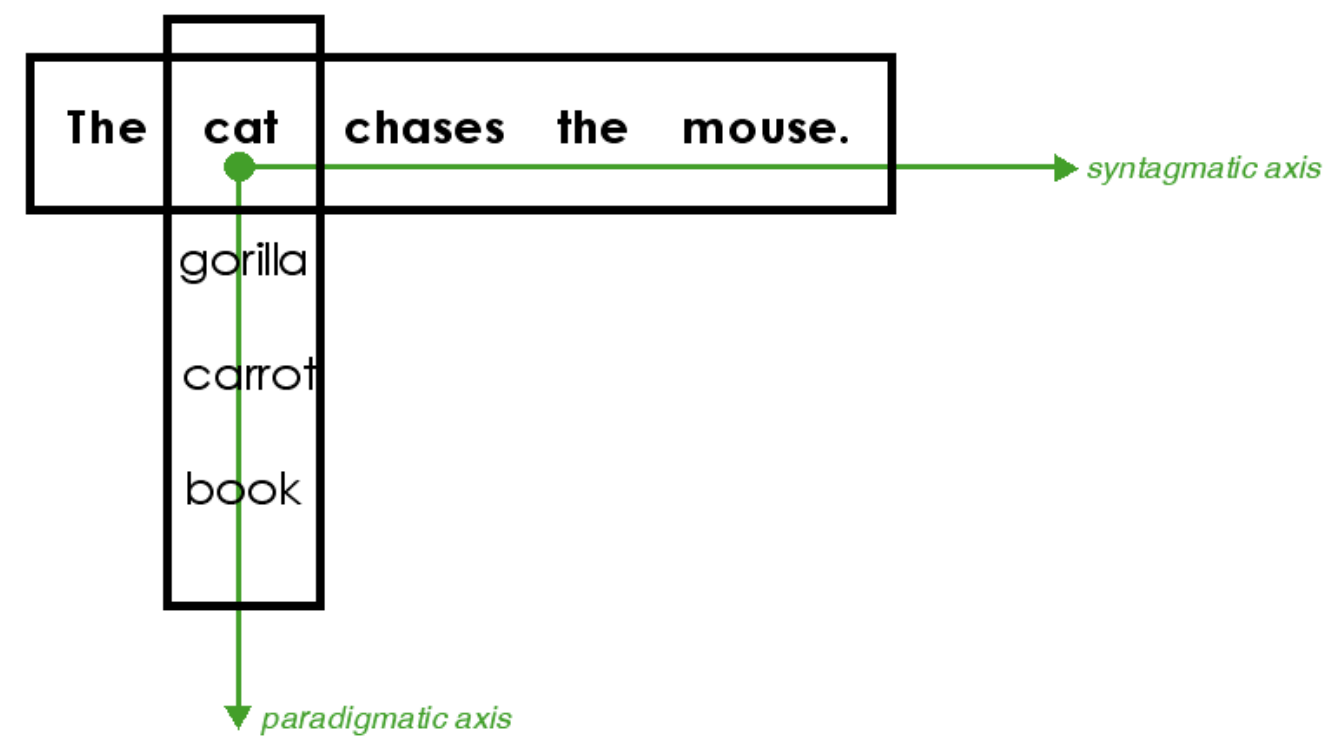

Figure 1.1: Syntagmatic and paradigmatic structuralist axes.

at the level of meaningful signs, the axes specify language at every level of structure.

With an understanding of this terminology, grammatical classes can thus be defined: grammatical classes are the way languages organize ideas into paradigmatic classes. A paradigmatic class is a set of linguistic units with potential for constructing the same (relevant) indexical relations with other linguistic units, or, equivalently, with the same set of potential syntagmatic frames. In comparing any two languages, it is evident that a given linguistic unit does not have identical potential for indexical relations in each language. Consider for example the following two, roughly denotationally equivalent, sentences in Spanish and English: 


\section{Spanish:}

$\begin{array}{ll}\text { Yo } & \text { desayun-o } \\ \text { 1SG.NOM } & \text { eat.breakfast-1SG. }\end{array}$

\section{English:}

\section{I eat breakfast}

In Spanish, the idea of <breakfast $>$ is grammaticalized as part of the verb whereas, in English, it is grammaticalized as a noun, a separate lexical item from the verb eat. Consequently, the linguistic units /desayuno/ and /breakfast/ do not have the same set of potential syntagmatic frames in their respective languages.

Whorf elaborated on this notion of grammatical categories, in one way, by distinguishing between two types: OVERT ${ }^{12}$ and COVERT ${ }^{13}$. Overt grammatical categories are paradigmatic classes in which the members share a formal marker that indicates their commonality. Whorf refers to such grammatical categories as "phenotypes" (72). In English, the class of plural nouns is an example of a phenotype (Foley 200). Plural nouns in English form a paradigmatic class, and nearly every plural noun is marked by the suffix '-s.' In addition to being identified by a formal marker, the plural noun phenotype also has "a clearly apparent class meaning" (Whorf 72). In the case of the plural phenotype, the class meaning is "more than one." In opposition to phenotypes are what Whorf refers to as covert grammatical categories or "cryptotype" (70). A cryptotype is a grammatical class in which the members do not share a formal marker. Rather, a cryptotype is only identifiable by analyzing the set of the potential syntagmatic frames for a given morpheme. To illustrate this type of grammatical category, Whorf provides the example of the class of "transitive verbs of covering, enclosing, and surface attaching meaning" in English (71). Verbs of this nature, argues Whorf,

\footnotetext{
12 "An overt category is a category having a formal mark which is present (with only infrequent exceptions) in every sentence containing a member of the category" (Whorf 88).

13 "A covert category is marked, whether morphemically or by sentence pattern, only in certain types of sentences and not in every sentence in which a word or element belonging to the category occurs" (Whorf 89).
} 
can be accompanied by the prefix 'un-,' while other verbs cannot. Thus the verbs uncover, undress, and untangle are grammatical while the verbs *unbreak, *unheat and * unspill are not. Based on the observation that this certain subset of transitive verbs is not permissible in a syntagmatic frame, Whorf concludes that they form a cryptotype. Like phenotypes, members of a cryptotype share a meaning, but this meaning is "a submerged, subtle, and elusive meaning, corresponding to no actual word" (70). From Whorf's distinction of overt and covert grammatical categories, it is evident that grammatical categories in different languages differ not only in content but also in type.

It is the notion of the covert grammatical categories that allows Whorf to relate the claims of relativity at the level of langue to parole. Whorf argues that speakers of a given language tend to employ words of -typic categories (phenotype and cryptotype) in structurally similar ways. That is, they use words that share membership to a -typic category in the same syntagmatic frames. Whorf argues, for example, that in English the word /time/ and certain words of "substance"14, such as /milk/, are members of a cryptotype (142-143). Evidence for their shared category membership comes from their common potential to fit in the syntagmatic frame / a [quantifier] of words of a -typic category in the same syntagmatic frame as FASHIONS OF SPEAKING (158). Thus, because different languages contain different -typic categories, speakers of different languages have different fashions of speaking. This is, in essence, a claim of linguistic relativity at the level of parole.

Fashions of speaking, by themselves, are not a particularly significant observation, but merely a statement of the consequences of grammatical categories at the level of

\footnotetext{
${ }^{14}$ Specifically, the relevant category of "substance" words is MASs NOUN. Mass nouns are nouns "which the speaker treats as continuous entities, having no natural bounds (contrasting with separable 'countable' quality of CounT NOUnS)" (Crystal, Dictionary 284). Note, however, that despite these semantic characteristics, the category is defined only by shared potential to fit in a set of syntagmatic frames.
} 
parole. In "Whorfianism and the Linguistic Imagination of Nationality," Silverstein provides a clear account of how the claim of relativity at the level of langue and the claim of relativity at the level of parole produce relativity in habitual thought. Silverstein argues that sociocultural conceptualizations of reality are projected from fashions of speaking and are derived, ultimately, from grammatical categories.

To best understand Silverstein's argument, an understanding of Peircean terminology is necessary. A sign RELATION (Fig. 1.2) for Peirce contains three elements: an OBJect ${ }^{15}$, a RePRESENTAMEN ${ }^{16}$, and an Interpretant ${ }^{17}$. In terms of language,

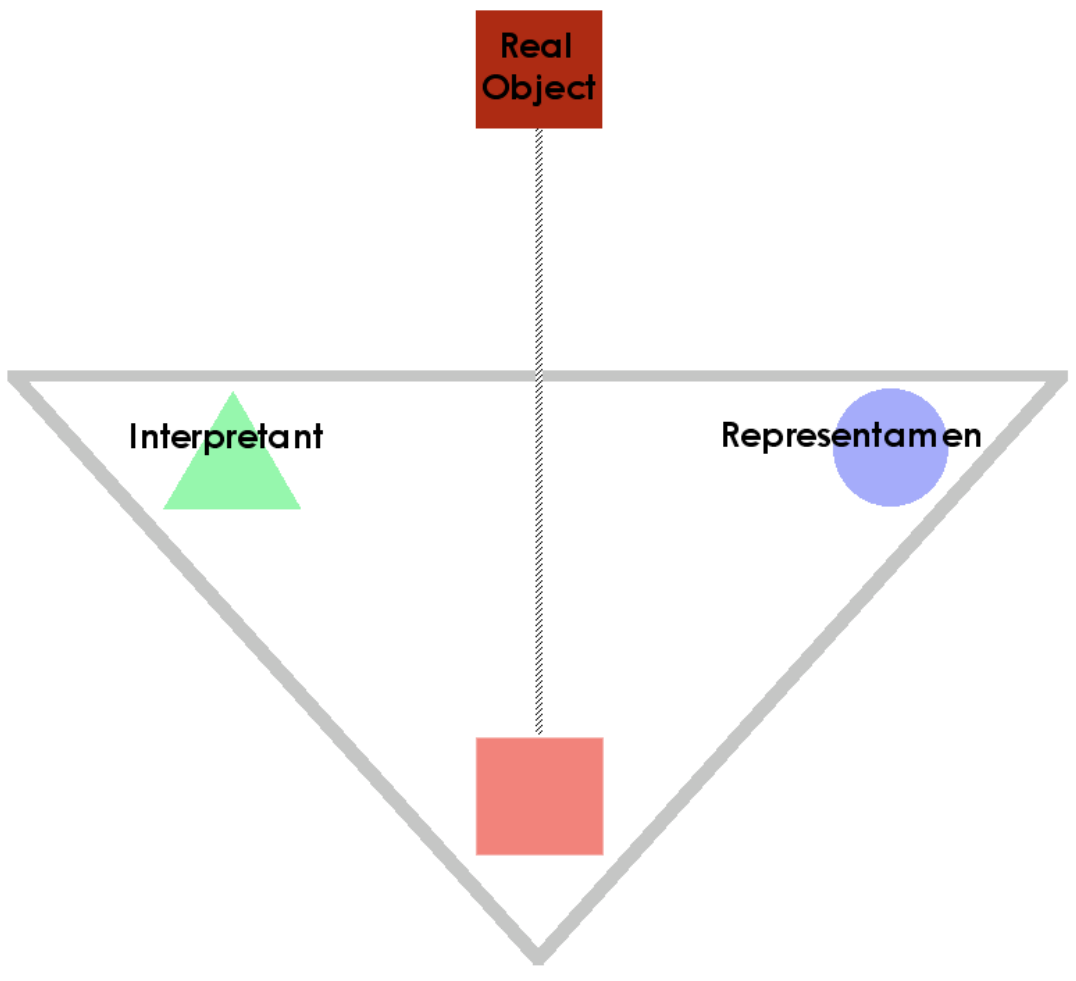

Figure 1.2: Peircean sign relation.

\footnotetext{
15 "A sign stands for something to the idea which it produces, or modifies. Or, it is a vehicle conveying into the mind something from without. That for which it stands is called its object" (Peirce, Commens, CP 1.339).

16 "A sign, or representamen, is something which stands to somebody for something in some respect or capacity. It addresses somebody, that is, creates in the mind of that person an equivalent sign, or perhaps a more developed sign" (Peirce, Commens, CP 2.228).

17 "The Sign creates something in the Mind of the Interpreter, which something, in that it has been so created by the sign, has been, in a mediate and relative way, also created by the Object of the Sign, although the Object is essentially other than the Sign. And this creature of the sign is called the Interpretant" (Peirce, Commens, EP 2:493-4).
} 
linguistic form is the Representamen, the idea produced as a result of experiencing the Representamen is the Interpretant, and the Object is the concept denoted by the linguistic form. To distinguish the three parts of the sign relation, the sign relation for the linguistic form cat is given in Fig. 1.3. Here, the form / cat/ at the level

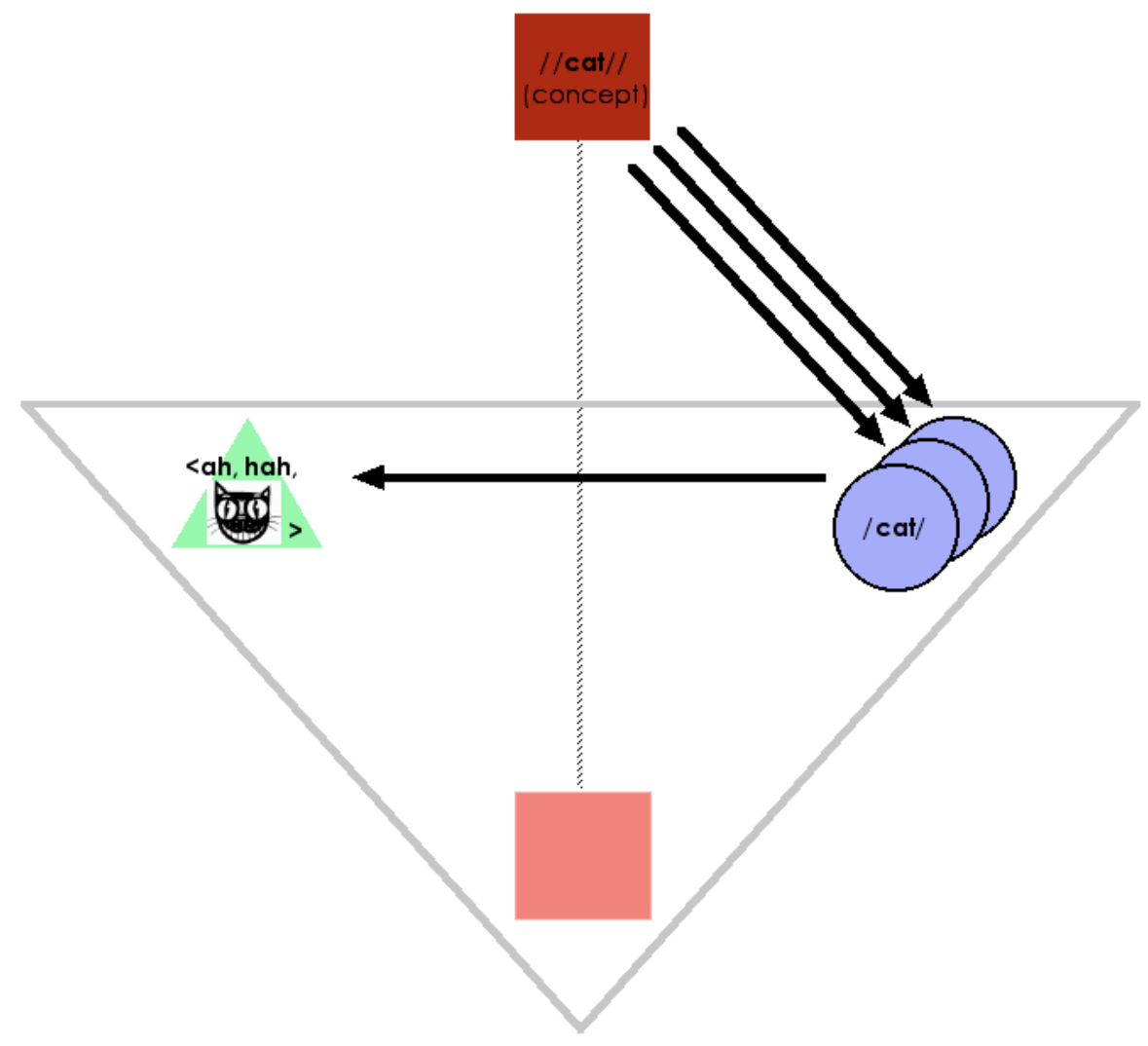

Figure 1.3: Peircean sign relation for /cat/.

of type is the Representamen, the Object of the sign is the concept of //cat//, and the Interpretant is the idea of <cat $>$ which is brought into the mind of the interpreter (the precise character of which depends on both the language structure and the experiences of the interpreter). Peirce categorizes sign relations, in part, by the relationship between the Object and the Representamen (Peirce calls this the SECOND Trichotomy). A sign relation is said to be ICONIC if the Object and Representamen are related by the identity of qualities. In an INDEXICAL sign relation, the Object and Representamen are related by contiguity. In a SYMBOLIC sign relation, to fill out the 
paradigm, the Object and Representamen are both type-level classes: The Object is a concept-type and the Representamen is a form-type. The two classes are related by neither similarity or contiguity, but by an arbitrary convention. Saussure's principle of arbitrariness (pg. 9) characterizes this relationship. In the sign relation for /cat/, the Representamen /cat/ (a class) and the Object //cats// (a class) are related by convention. The sign relation is thus symbolic.

Silverstein's account of the mechanism by which fashions of speaking influence thought can be understood, I argue, as a case of diagrammatic reasoning. A DIAGRAM $^{18}$ is the second hypoicon, or subtype, in Peirce's tripartite of ICONS ${ }^{19}$. The three hypoicons are distinguished by how, or in what sense, the Object and the Representamen in the iconic sign relation are identical. The diagrammatic hypoicon is grounded in the Representamen. It is characterized by identity of indexical relations (real and potential) in the Representamen and the Object. Thus, in a diagram, two forms $\mathrm{A}$ and $\mathrm{B}$ are related in manner $\mathrm{X}$ in both the Representamen and the Object. For example, California and Oregon are related on a map (a Representamen) in that Oregon is north of California, and this relationship is identical to the geographical relationship (the Object). The map is thus a diagram of Oregon and California. In the case of language structure, "indexical relations" are synonymous with "syntagmatic relations." Grammatical classes can therefore be identified with diagrammatic classes: a grammatical class contains words with the same potential for indexical relations, or syntagmatic relations.

Crucially, Stjernfelt argues that "the core point of Peircean diagrammatology" is that the diagram is "a vehicle for mental experiment and manipulation" (99). The value of the diagram lies in the possibility "to manipulate the sign so that new information as to its object appears"; in the possibility of novelty (90). Stjernfelt suggests

\footnotetext{
18 "[Hypoicons] which represent the relations, mainly dyadic, or so regarded, of the parts of one thing by analogous relations in their own parts, are diagrams" (Peirce, Commens, CP 2.277).

19 "An $i$ con is a representamen which fulfills the function of a representamen by virtue of a character which it possesses in itself" (Peirce, Commens, CP 5.73).
} 
that this possibility is most clearly realized in mathematics, although it functions in the same way for all diagrammatic icons: "the manipulation of an equation or of an algebraic statement is [in some sense] perfectly equal to the manipulation of a picture or a text or any other icon in order to make it reveal some more similarities than immediately observable" (79). With the aim of creating novel understanding, thus, speakers experiment with diagrammatic classes - namely, grammatical classes. That is, they engage in deductive reasoning by taking a grammatical class as a premise and considering what relations follow.

Silverstein argues, thus, that sociocultural conceptualization of reality are produced through diagrammatic reasoning. The diagrammatic reasoning occurs implicitly in the history of a fashion of speaking. The premises to the diagrammatic reasoning are (i) the relationship between the Representamen and Interpretant for a token sign, and (ii) the relationship between two signs in a grammatical category (a diagrammatic class). In the case of the first premise, the token must be a member of a grammatical category of a certain kind. It must, to be part of the premise in the diagrammatic reasoning process, denote a clearly identifiable Object in the world. To illustrate the logic behind the SOCIOHISTORICAL DIAGRAMMATIC REASONING PROCESS, consider the sign relation for the sign [that cup]. The utterance [cup] is a token of the requisite type: a [[cup]] is clearly identifiable Object in the world. The sign [that cup] is, in Peircean terminology, a DICENT InDExiCAL SInsign. The term SINSIGN denotes Representamen that exist at the level of Secondness (cf. LEGISIGN, which denotes Representamen at the level of Thirdness) ${ }^{20}$. The Representamen [that cup] is thus a sinsign because it is an actual utterance. The sign relation is indexical because the relationship between the Representamen and the Object is characterized by continuity. That is, the utterance [that cup] occurs in the presence of an intersubjectively available [[cup]]. Finally, and most significantly for diagrammatic reasoning,

\footnotetext{
${ }^{20}$ The terms SINSIGN and LEGISIGN are synonymous with TOKEN and TYPE, respectively.
} 
the relationship between the Representamen and the Interpretant is a dicent. That is to say, the Representamen partially determines the Interpretant, the idea in the mind of the interpreter. The relationship between [that cup] and the idea it brings to mind in the interpreter is the first premise. The second premise is the relationship between two signs in a grammatical category. For purposes of illustration, consider the grammatical category containing the signs cup and pound. Their ability to fit into the same syntagmatic frame demonstrates their common grammatical category. This is illustrated in the following two noun phrases with the syntagmatic frame / $a$ of [mass noun]/: (1)/a cup of sugar/ (2)/a pound of butter/.

Through a process of diagrammatic reasoning these two premises lead speakers, implicitly, to the conclusion that $[[$ pound] $]$ and $[[$ cup $]]$ are, in some way, conceptually the same. Because the grammar of English presents its speakers with the possibility of talking about a [[pound]] in the same way they talk about a [[cup]], speakers will be inclined to do so. Initially, talking about a [[pound]] in the same way as [[cup]] will be conceptualized as a conscious choice of a metaphorical way of talk. Over the course of a history of sociocultural members talking in this manner, this way of talk will no longer be conceptualized as a "metaphor" but as a "literal' formulation of a fundamental aspect of the universe of experience" (Silverstein, Whorfianism 100); it will become a fashion of speaking. Thus, the conclusion to the diagrammatic reasoning process: a link between [pound] and the Interpretant associated with [cup]. That is, speakers conceptualize the "aspect of the universe of experience" related to pound $<$ pound $>$ as, by analogy, the same one connected to $<$ cup $>$. A history of sociocultural practice is therefore the embodiment of a diagrammatic reasoning process. It is an implicit experimentation with the premises of a relationship between $[\mathrm{x}]$ and $[\mathrm{y}]$, which shared a grammatical category, and $[\mathrm{x}]$ and its Interpretant. The relationship between $[\mathrm{y}]$ and the Interpretant of $[\mathrm{x}]$ is the conclusion to this reasoning. A speaker who uses a fashion of speaking, without considering it as such, assumes 
this conclusion of the sociohistorical diagrammatic reasoning process. Thus, the intersection of the structure of language with discursive interaction, and the history of such, generates different fashions of speaking. These fashions of speaking, in turn, generate "a relativity of 'habitual thought'" (Silverstein, Whorfianism 98).

Whorf discusses what "aspect of the universe of experience" might be shared in the understanding of nouns like /cup/ and/pound/. He suggests that /cup/ and /pound/, as count nouns, are distinguished from /sugar/ and /cup/, as mass nouns. He argues that as a result of syntagmatic frames such as / $a_{---_{--}}$of [mass noun]/ (and the sociohistorical diagrammatic reasoning process), count and mass nouns become semantically distinguished as "containers" and "content," respectively (141). "Our language pattern," Whorf observes, "often requires us to name a physical thing by a binomial that splits the reference into a formless item plus a form" (141). Thus, suggests Whorf, words such as /sugar/ and /cup/ are understood for English speakers as "containers" or "form." It is important to keep in mind, however, that Whorf's central claim is not what the shared "aspect of the universe of experience" is as a result of fashions of speaking, but rather that there exists a shared "aspect of the universe of experience."

The process of a sociohistorical diagrammatic reasoning is represented schematically in Fig. 1.4. Two sign relations are represented: The top grey triangle represents the [cup] sign relation and the bottom grey triangle represents the [pound] sign relation. Note that the relationship between the Representamen [cup] and the Object $[[$ cup $]]$ is indexical. This reflects the fact that the Object [[cup]] can be "intersubjectively available" when the speaker utters [cup]. That is to say, should there be any confusion about the denotation of [cup], the speaker could point to a [[cup]] sitting on the table. The Object and the Representamen are thus contiguous. In contrast, within the sign relation [pound] the Object is unclear. This is due, in part, because $[[$ pound $]]$ can not be intersubjectively available in the same way that $[[$ cup $]]$ can. It is 


\section{[cup] sign relation}

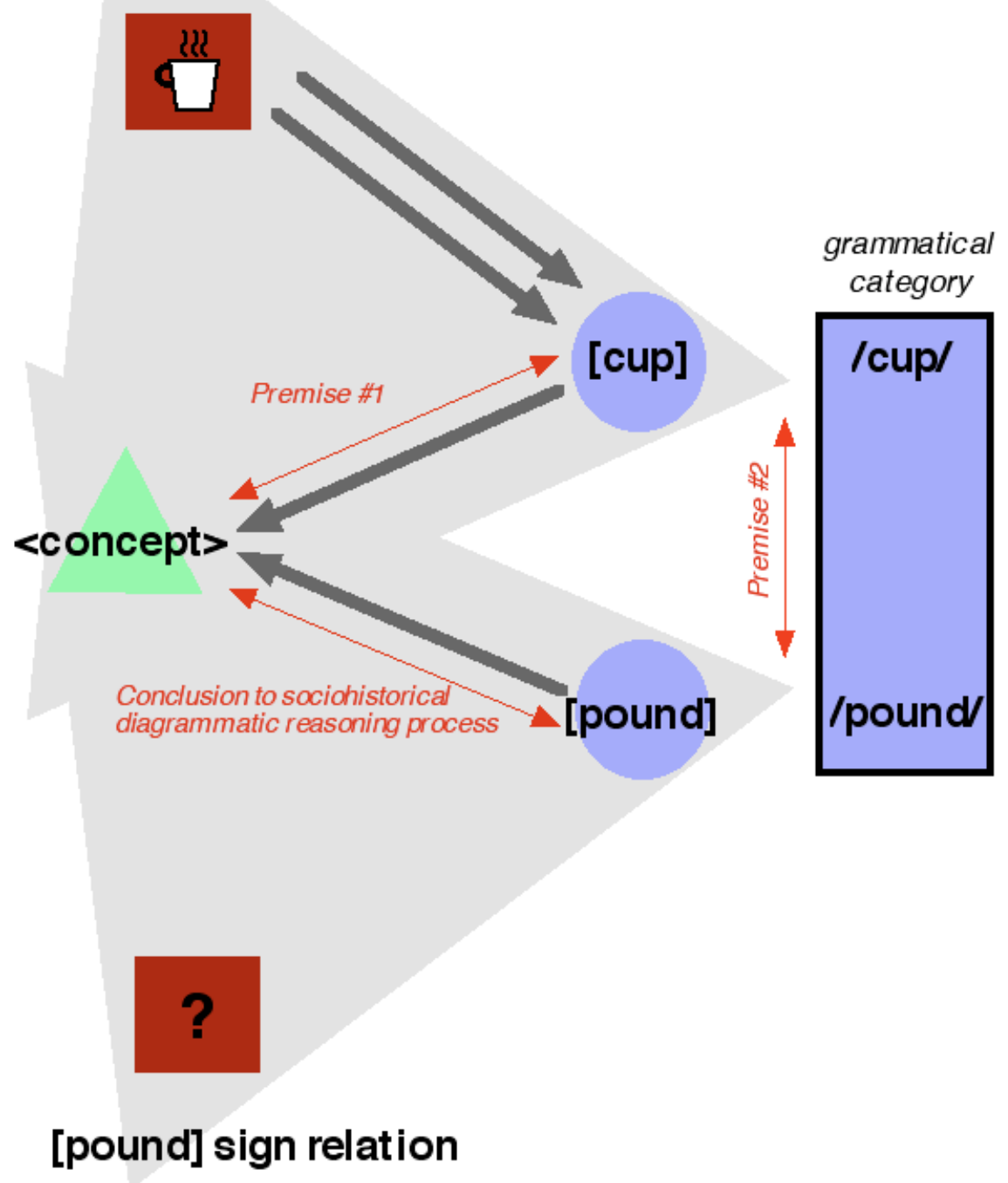

Figure 1.4: The sociohistorical diagrammatic reasoning process. 
this ambiguity of [[pound]] that allows for indirect conceptualization through a sociohistorical diagrammatic reasoning process. The first premise to the argument thus is the relationship between the Representamen [cup] and the Interpretant $<$ cup $>$. The second premise is the relationship between [cup] and [pound] at the level of langue. This relationship is that of a shared grammatical category. It is the conjunction of these two premises that, over time, produces the conclusion to the diagrammatic reasoning process: the relationship between the Representamen [pound] and the Interpretant $<$ cup $>$. It should be noted that the Interpretants of [cup] and [pound] are not entirely identical, as is suggested by the diagram, but rather their Interpretants share some critical feature, some "aspect of the universe of experience."

Thus, in their "habitual thought," speakers understand the grammatical category shared by $[\mathrm{x}]$ and $[\mathrm{y}]$ to be a diagram of "the universe of experience." That is, they tend to reverse the direction of causality or implication: they tend to believe that $[\mathrm{x}]$ and $[y]$ manifest in the same discursive structures because they reflect, in some sense, the same reality. They fail to recognize that the understanding of $[\mathrm{y}]$ as denoting the same kind reality as $[\mathrm{x}]$ is a product of a sociocultural history of discursive practice. Speakers' "error," then, is the failure to recognize the sociocultural history that over time renders the idea that "talk of $\mathrm{x}$ like $\mathrm{y}$ " is a metaphor as invisible.

In sum, then, it may be said that there is 'relativity' pertaining to language in two respects: grammatical categories and fashions speaking. These two sorts of relativity in language correspond to two different ontological levels in language: langue and parole. Boas and Sapir are primarily responsible for the claim of linguistic relativity at the level of langue. The claim of relativity at the level of langue is by itself of little consequence for (habitual) thought. In order to explain the way in which relativity in language structure produces relativity in thought, Whorf made a claim of relativity at the level of parole: speakers of different languages use different fashions of speaking. Whorf argues that fashions of speaking are a consequence of the relativity at the 
level of langue. More specifically, he argues that they are a consequence of different cryptotypes in languages. In his interpretation of Whorf, Silverstein provides an account of how fashions of speaking over time produce different habits of thought, or conceptualizations. Silverstein's account can best be understood as diagrammatic experimentation. 



\section{Chapter 2}

\section{Neo-Whorfian Linguistic Relativity}

Michael Silverstein is the central figure in Neo-Whorfian thought. His contribution to the field of linguistic relativity is, as he states, "to generalize Whorf's observation for the whole range of functions of speech" (Awareness 400). That is, to generalize the claim of linguistic relativity from the symbolic realm of linguistic meaning to the indexical realm. Thus, what is 'neo' about Neo-Whorfianism is the semiotic domain of language which is at issue. What is 'Whorfian' about Neo-Whorfian thought is the idea of grammatical categories that lie beneath the plane of speaker awareness. By adopting the notion of systematically limited linguistic awareness, Silverstein argues for linguistic relativity at the level of indexical meaning. His claim of relativity at the level of indexical meaning can be situated with respect to his theory of culture.

\subsection{Formal Semiotic Grounding}

In "The Limits of Awareness," Silverstein outlines Neo-Whorfian theory following a line of reasoning parallel to his Whorfian predecessors. Whorfian thought may be summarized by two defining notions. First, Whorf contrasts two formal linguistics categories, covert and overt grammatical categories, that correspond to different degrees of speaker awareness. Second, Whorf argues that the linguistic category of 
limited awareness, the covert grammatical category, facilitates a unique pattern of habitual thought. Silverstein adapts and applies these two Whorfian notions to the indexical realm of language meaning and considers the distinct implications that follow. Silverstein concludes that "the outcome of conscious reflection of language will be skewed in favor of [grammatical categories] which are more accessible" (Foley 213). Consequently, because grammatical categories vary across languages, speakers of different languages will differ in their awareness of indexical meaning.

Franz Boas is responsible for the central role of "awareness" in the theory of linguistic relativity. Boas observed that the "laws of language remain entirely unknown to the speakers" (63). He argues that, in contrast to "all other ethnological phenomena," "the use of language is so automatic that the opportunity never arises for the fundamental notions to merge into consciousness" $(63,68)$. Because linguistic phenomena is unconscious, argues Boas, it is not subject to "the misleading factors of secondary explanations which are so common in ethnology" (70). For this reason, language can be studied as a means to gain direct access to "a culture's symbolic constructions" (Foley 196). It is this notion that motivates Whorf's distinction of covert and overt grammatical categories and, in turn, motivates the core argument in Neo-Whorfian thought.

Silverstein considers the Boasian notion of awareness within the realm of indexical meaning. Indexical meaning is a dimension of every "meaningful" linguistic form. By supplementing symbolic meaning, indexical meaning allows speakers to connect linguistic forms to things in the world. To illustrate the difference between indexical and symbolic meaning, consider the following definition of a novel word:

zerick (definition \#1): The name of the crast crugal bage on the proll wune murse of the vabe grotch fune.

I have here, in a sense, given a meaning to the novel word zerick by relating it to different linguistic forms. This definition corresponds to the symbolic meaning of the 
form zerick. However, because you have no experience with //crast//, //crugal//, //bage//, etc., you have no understanding of what a //zerick// is (other than that its linguistic representation falls into the grammatical category NOUN, and has the feature SINGULAR). To understand what a //zerick// is, the indexical dimension of meaning is necessary. The indexical meaning of zerick can be acquired from either experiences with a //zerick//, or, in the case of a definition, experience with the Objects of the defining linguistic terms. In my definition above, neither of these requirements are met, and thus, you have no way to relate the form [zerick] to the world. I can provide indexical meaning to the form [zerick] by allowing you to directly experience a //zerick// by seeing one, as is the case in Fig. 2.1, or by employing words in the definition which you already have experience with.

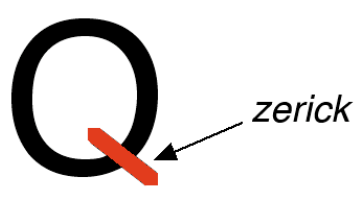

Figure 2.1: A //zerick//.

zerick (definition \#2): The name of the small diagonal line on the bottom right corner of the capital letter "Q".

In this second definition, you are able understand what a //zerick// is because you have, via some sort of experience, indexically-grounded knowledge of the words small, diagonal, line, etc.

The indexical dimension of meaning is the basis of culturally-constituted linguistic meaning, the type of meaning concerning Silverstein in "The Limits of Awareness." Specifically, Silverstein addresses what is called PRAGMATIC meaning: "how speech forms are used as effective action in specifiable cultural contexts" (Awareness 382). This type of meaning, he states, "can be described as rules linking certain culturallyconstituted features of the speech situation with certain forms of speech" (383). In the 
case of the utterance [My, it is cold in here] uttered by a guest sitting in a house with an open window, for example, the cultural rule is that, given this speech form and context, the guest would like the window to be closed. Silverstein's claim of relativity, however, is not at the level of pragmatics, but at the level of METAPRAGMATICS. Metapragmatics is discourse about pragmatics; discussion of the indexical "rules." It is, as Silverstein states, "talking about saying"" (382). Thus, to utter [A guest who says 'My, it is cold in here' when sitting next to an open window means that she wants the window to be closed], as I effectively did above, is to engage in metapragmatic discourse.

With an understanding of this semiotic terminology, Silverstein's central claim can be stated more precisely: "For the native speaker, the ease or difficulty of accurate metapragmatic characterization of the use of the forms of his or her own language seems to depend on certain general semiotic properties of the use in question" (Awareness 383). Silverstein identifies three semiotic properties of pragmatic forms which affect a speaker's ability to engage in "accurate metapragmatic characterization": (i) UNAVOIDABLE REFERENTIALITY, (ii) CONTINUOUS SEGMENTABILITY, and (iii) RELATIVE PRESUPPOSITION. Utterances that are characterized by these three semiotic properties, argues Silverstein, tend to be highly accessible to speakers' metapragmatic awareness.

Unavoidable referentiality is "the property of those pragmatic (effective contextdependent) signals that are automatically identified by identifying the elements of the speech that refer, or describe" (Silverstein, Awareness 386). Restated, this property applies to forms in which a pragmatic marker and a form with denotational value coincide. This property is exemplified by an utterance of the Spanish form usted, the second-person singular "formal" pronoun. Pragmatically, the form usted means that the speaker is socially distant from the interlocutor. The form usted also means, that is, denotes, [[the speaker's interlocutor]]. Because the pragmatic marker, usted, 
and the form with denotational value, usted, are identical, the pragmatic marker is unavoidably referential.

Second, continuous segmentability is "the property of those pragmatic signals that can be identified as continuous stretches of actual speech segmentable as overt meaningful units of the utterances in which they occur" (Silverstein, Awareness 387). More clearly, this principle may be thought of as the property of pragmatic signals for which the "overt meaningful units" have an unbroken chain of concatenated indexical relations. Thus, as one moves along the "chain," the sentence, from left to right, a referential unit $\mathrm{X}$ is said to be "unbroken" if when a second referential unit $\mathrm{Y}$ is reached $\mathrm{X}$ is complete. To illustrate this principle, Silverstein contrasts two "referential units" within the utterance [The man was walking down the street]: (i) the event [the man walking down the street] and (ii) the Progressive aspect. In the first case, each meaningful unit contained within the utterance (phrases (the man), words (The, Man), and suffixes (-ing)) is formed by an unbroken chain of indexical relations (387). Silverstein thus labels the entire utterance [The man was walking down the street] as continuously segmentable. In contrast, the indexical chain of the referential unit [was -ing] is "broken" by the intervening form [walk]. Silverstein therefore argues that "the single referential unit expressing the Progressive aspect, the complex of forms 'was -ing,' is not continuously segmentable"; is discontinuous (387). In more illustrative terms, thus, [the man walking down the street] is an unbroken chain of concatenated indexical relations and [was -ing] is a broken chain.

Finally, Silverstein defines the third property, relative presupposition, as "a relationship whereby a specific effective instance of a pragmatic signal is linked to and requires, for its effect, some independently verifiable contextual factor or factors" (Awareness 387). This property is exemplified by the demonstratives this and that. To be effective pragmatic signals, these forms must be linked to minimally one of two potential contextual factors: (i) an intersubjectively available non-speech entity, or 
(ii) a prior discourse referent. In the utterance [This paper is white], for example, the token [this] satisfies the requirement of relative presupposition because [[the paper on page 30]] is a non-speech entity that is intersubjectively available. In opposition to relative presupposition is the property RELATIVE CREATIVITY. Pragmatic markers which are relatively creative are not linked to an "independently verifiable contextual factor," but rather "bring some contextual factor into existence" (387). Silverstein argues that deference and politeness markers, like professor in the utterance [Prof. Rogers], bring into existence "the contextual dimensions of power relationship and familiarity between him/herself and the addressee" (388). Pragmatic forms which are relatively presupposing are more subject to metapragmatic awareness than those which are relatively creative.

To illustrate these three properties, Silverstein provides examples of two languages which differ on all three semiotic dimensions and, consequently, whose speakers have different degrees of metapragmatic awareness. Here, I outline the evidence from both languages for the first property, unavoidable referentiality. The "mother-in-law" style of the Dijirbal language of North Queensland, Australia exemplifies the principle of unavoidable referentiality. The mother-in-law style has a distinct set of vocabulary items from the "everyday" style. The form denoting a //louse//, for example, is /bayi marbu/ in the everyday style and /bayi dimaninj/ in the mother-in-law style. In addition, the mother-in-law style has a very specific context of usage from the everyday style: It is used only when one's mother-in-law is within earshot. Thus, each utterance in the mother-in-law style has a distinct pragmatic meaning: it indexes that one's mother-in-law is within earshot. The form marking this pragmatic meaning, in the case of example above, is the entire phrase /bayi dimaninj/ The pragmatic marker thus coincides with the referential form; it is unavoidably referential. Consequently, in the context of elicitation work, Silverstein argues it is clear that speakers of the mother-in-law style "are aware of the difference of context signaled by these 
vocabulary switches" (Awareness 385).

As a contrasting case, Silverstein presents the Native American language Kiksht. In Kiksht, speakers have the grammatical ability to express that "a referent of some lexical item is large for what it is, or to excess, if an activity; that it is repulsive to the speaker" (Awareness 389). This form is termed AUGmentative ${ }^{1}$. Alternatively, speakers may express in the grammar the "feeling that the referent is small, or subtle; that it endears the speaker" by using the DIMINUTIVE ${ }^{2}$ form (389). Because these forms index a feature of the speech context, namely, the speaker, they mark pragmatic meaning. In Kiksht, the augmentative and diminutive forms are derived through regular gradation of sound features. In the example below, the augmentative and diminutive forms of /id-mí-pš / ("your foot") are derived through /b/>/p/>/p|/ gradation sound change.

$$
\begin{aligned}
& i d-m i-\boldsymbol{b} \check{z} \quad i d-m i-\boldsymbol{p} \check{s} \quad i t^{\prime}-m i-\boldsymbol{p} \mid s \\
& \text { AUGMENTATIVE }>\text { NEUTRAL }>\text { DIMINUTIVE }
\end{aligned}
$$

Crucially, the augmentative and diminutive pragmatic markers (/b/ and /p|/, respectively) do not have referential value. That is, they are not unavoidably referential. Consequently, efforts to elicit accurate metapragmatic discourse describing the augmentative and diminutive forms are unsuccessful. For instance, in the case of even a particularly "sensitive" Kiksht consultant, the speaker could report that "all the forms [Silverstein] produced with diminutive effects 'sounded kinda cute,' but she just could not grasp the metapragmatic task of producing them on demand, though her spontaneous speech was replete with examples" (390).

\footnotetext{
1 "A term used in morphology to refer to an affix with the general meaning of 'large,' used literally or metaphorically (often implying awkwardness or ugliness)" (Crystal, Dictionary 42).

2 "A term used in morphology to refer to an affix with the general meaning of 'little,' used literally or metaphorically (as a term of endearment)" (Crystal, Dictionary 139).
} 
Based on evidence such as this, Silverstein concludes that speakers' "pragmatic awareness of social action," is limited, but, crucially, that the limits are "definable, constrained, and semiotically based" (Awareness 401). That is, as Foley states, "Silverstein's ideas boil down to another claim that features of structure within language lead to concepts about the structure of the "world'" (213). The ways in which Silverstein's theory is "another claim" of Whorfian ideas become less opaque, I argue, by highlighting the role of unavoidable referentiality in Silverstein's theory. Silverstein too seems to emphasize this property. In concluding the paper, he states: "the other functions of language are always being assimilated to reference in terms of native speaker awareness, and are in fact subject to conscious metapragmatic testimony only to the extent that they are assimilable to reference, or 'ride along on' referential structure" (401).

Thus, framed in terms of the principle of unavoidable referentiality, Figure 2.2 presents Silverstein's Neo-Whorfian theory in a parallel structure to that of Whorfian theory. Both theories are grounded semiotically in grammatical categories. Here, I

\begin{tabular}{|c|c|c|c|c|}
\hline & Linguistic Form $X$ & Relation & Linguistic Form $Y$ & Consequence \\
\hline \multirow{2}{*}{$\begin{array}{l}\text { Whorfian } \\
\text { Linguistic } \\
\text { Relativity }\end{array}$} & referential form \#1 & $<O V E R T\rangle$ & referential form \#2 & $\begin{array}{c}\text { high awareness of grammatical category; } \\
\text { low tendency toward diagrammatic } \\
\text { experimentation }\end{array}$ \\
\hline & referential form \#3 & $<$ COVERT $>$ & referential form \#4 & $\begin{array}{c}\text { low awareness of grammatical category; } \\
\text { high tendency toward diagrammatic } \\
\text { experimentation }\end{array}$ \\
\hline \multirow{2}{*}{$\begin{array}{l}\text { Neo- } \\
\text { Whorfian } \\
\text { Linguistic } \\
\text { Relativity }\end{array}$} & referential form & $\begin{array}{c}<\text { <OVERT> } \\
\text { (pragmatic marker coincides with form } \\
\text { with denotational value) }\end{array}$ & pragmatic marker \#1 & $\begin{array}{l}\text { high awareness of grammatical category; } \\
\text { high metapragmatic awareness }\end{array}$ \\
\hline & referential form & $\begin{array}{c}<\text { COVERT } \\
\text { (pragmatic marker does not coincide } \\
\text { with form with denotational value) }\end{array}$ & pragmatic marker \#2 & $\begin{array}{c}\text { low awareness of grammatical category; } \\
\text { low metapragmatic awareness }\end{array}$ \\
\hline
\end{tabular}

Figure 2.2: A parallel presentation of Whorfian and Neo-Whorfian theory.

represent only two members in a grammatical category, under the columns "Linguistic Form X" and "Linguistic Form Y." At issue for both theories is the transparency of the relation of the two linguistic forms for the native speaker, relative to the analyst. An overt relation between the two linguistic forms facilitates awareness of their shared grammatical category, while a covert relation obscures it. For Whorfian linguistic relativity, the two relevant linguistic forms in a grammatical category are referential. 
For Neo-Whorfian Linguistic Relativity, the grammatical category contains a referential form and a pragmatic marker. At the level of parole in Whorfian relativity, these structural facts affect speakers' tendency to engage in diagrammatic reasoning through fashions of speaking. At the level of parole in Neo-Whorfian relativity, these structural facts affect speakers' metapragmatic awareness. Thus, by framing Silverstein's theory in terms of unavoidable referentiality, clear parallels between Whorfian and Neo-Whorfian thought emerge.

Schematically, a framing of Silverstein's theory in terms of unavoidable referentiality allows the two theories to be presented simultaneously. In Fig. 2.3, three vertical

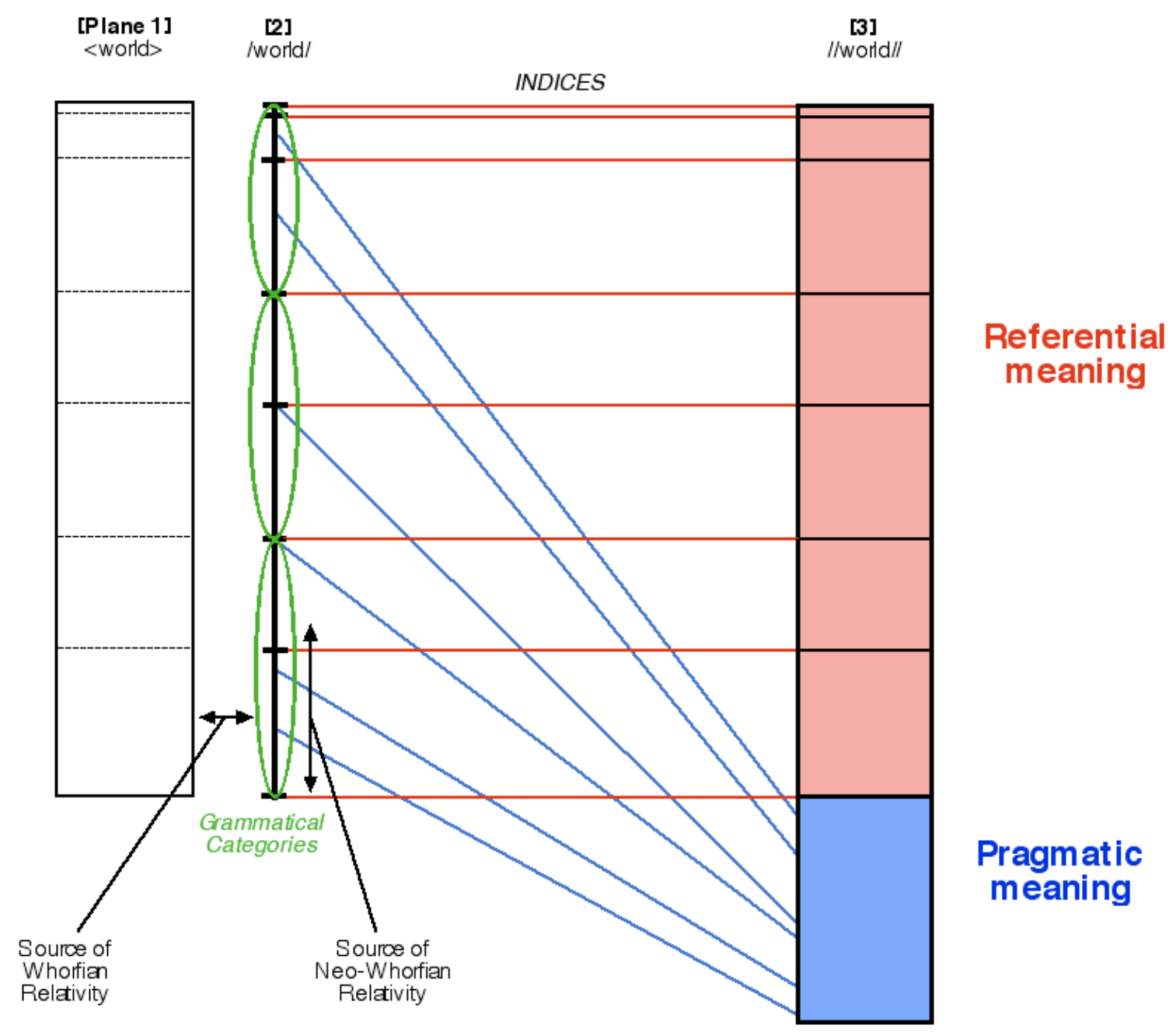

Figure 2.3: A diagram of the relationship between Whorfian and Neo-Whorfian theories of linguistic relativity. 
planes are represented, each corresponding to a different element in the Peircian sign relation. Plane [1] represents the world as interpreted, Plane [2] represents the world as it exists in language form (corresponding to the Representamen), and Plane [3] represents the world as an Object. Analytically, Plane [3], the plane of Objects, is an undifferentiated spectrum. Languages cut this spectrum into chunks, and they do it in different ways. The diagram represents one way of dividing this spectrum. Languages organize these chunks of meaning into different grammatical categories. Grammatical categories are represented by green ovals. Some of these grammatical categories are overt for the native speakers; others are covert. As is clear from the discussion of the word zerick (pg. 26), all symbols must be accompanied by an index in order to be effective signifiers in language. That is, all symbols must be accompanied by some sort of experience in order to have meaning (of the sort relevant in natural language). This is represented by the red horizontal lines extending from Plane [2] to Plane [3]. Relativity in language structure, thus, originates from the relationship between the world as an Object (Plane [3]) and the plane of form (Plane [2]). Relativity in habitual thought results from the mapping of relativity at the level of structure on to thought; the mapping of Plane [2] on to Plane [1]. This 'mapping' is the sociohistorical diagrammatic reasoning process. In Neo-Whorfian theory, the blue lines represent indexical relations from the plane of form to pragmatic meaning. The relevant form in the case of Neo-Whorfian theory is pragmatic markers. Pragmatic markers that "line up" with the forms of referential meaning facilitate metapragmatic awareness for the native speaker.

At at less-nuanced level, the two theories of linguistic relativity may be summarized by the conjunction of two claims: Each theory contains a claim of relativity which is governed by a claim of universality. In the symbolic realm, Whorf argues that there is diversity in language structure, but that the principles governing speakers' awareness of them - and, consequently, the tendency to engage in a diagrammatic 
reasoning — are universal. Similarly, in the indexical realm, Silverstein argues that speakers' metapragmatic awareness is, as Lucy states, "skewed differently depending on what particular categories and functions happen to be favored in their susceptibility to awareness in a given language," but that "the processes limiting or governing metapragmatic awareness are common across all languages" (119). Neo-Whorfian relativity can thus be viewed as a parallel formulation of Whorfian theory both in terms of the semiotic mechanisms at issue and the central argument structure.

Despite these predominant parallels, there is a significant point of contrast between the two theories: the nature of what is relative. In Whorfian relativity, the relativity lives in habitual thought. Silverstein's claim, in contrast, concerns speakers' "conscious construal of reality" (Lucy 121). These two objects of relativity differ crucially in the analytical status of the "chunk of meaning" at issue. In the case of Whorfian linguistic relativity, there is no analytical motivation for a chunk of meaning as such in a particular language. In making this point, Whorf states, "each language performs the artificial chopping up of the continuous spread and flow of existence in a different way" (Whorf 253). The "chopping up" is "artificial" in the sense that there is no a priori organization to reality and, thus, all ways of cutting up referential meaning are equally (un)motivated. The analyst's observation in Whorfian relativity, then, is that speakers confound two potentially, but not analytically, distinct pieces of referential meaning. In contrast, in Neo-Whorfian theory, the chunks of meaning at issue, indexical chunks of meaning, are analytically distinct. To illustrate this point, consider Silverstein's Kiksht example from above. Utterances of the augmentative and diminutive forms of foot index two different, analytically distinct, pragmatic meanings. Speakers who are not conscious of the pragmatic meaning of the diminutive form, for instance, are said to be metapragmatically unaware. In contrast, in the referential domain, speakers who talk about time in the same way they talk about count nouns are not said to be "referentially unaware." To do so would suggest 
that some languages denote reality better than others - a claim antithetical to the Whorfian project. Rather, a more correct characterization of speakers concerning relativity in the referential domain is that they are unaware of the referential uniqueness of their language. A claim of "unawareness of referential uniqueness" is qualitatively different from the Neo-Whorfian claim of "metapragmatic unawareness:" The former is a claim about awareness of cross-linguistic difference in meaning, and the latter is a claim about awareness of the existence of a meaning.

Figure 2.4 below contrasts the objects of relativity in Whorfian and Neo-Whorfian linguistic relativity. The left column represents habitual thought in the Whorfian do-

\begin{tabular}{|c|c|c|c|}
\hline \multicolumn{2}{|c|}{$\begin{array}{c}\text { Who rfian Linguistic Relativity } \\
\text { Habitual Thought }\end{array}$} & $\begin{array}{c}\text { Neo-Who rfian Linguistic Relativity } \\
\text { Construal of Reality }\end{array}$ \\
\hline Language $\mathrm{X}$ & Language $\mathrm{Y}$ & \multicolumn{2}{|c|}{ Language $\mathrm{X}$} \\
\hline
\end{tabular}

Figure 2.4: Contrasting representation of the objects of relativity in Whorfian and Neo-Whorfian thought.

main of linguistic relativity and the right represents the construal of reality in the Neo-Whorfian domain. In each domain, two abstract languages are compared: Language $\mathrm{X}$ and Language $\mathrm{Y}$. Lower case letters $a$ through $i$ denote meaning, and the subscripts $s$ and $i$ denote the type of meaning, symbolic and indexical, respectively. In the Whorfian domain, letters $a$ through $c$ form a spectrum of referential meaning. Languages $\mathrm{X}$ and $\mathrm{Y}$ organize this spectrum into grammatical categories in different ways. The organization into grammatical categories is represented by dashed ovals. Language $\mathrm{X}$ groups $a$ in its own grammatical category while Language $\mathrm{Y}$ groups $a$ and $b$ together. Thus, a speaker who is unaware of the covert grammatical category containing meaning $a$ is unaware of a "chunk of meaning," but crucially a "chunk of 
meaning" that is arbitrary. That is, the speaker is unaware that meaning a could, with equal (lack of) motivation, be categorized differently, as in Language Y. In the Neo-Whorfian domain, letters $d$ through $i$ represent analytically distinct chunks of indexical meaning. Their status as analytically distinct is denoted by solid circles. Silverstein's claim, thus, concerns whether speakers are consciously aware of the existence of these chunks.

Based on Silverstein's concern with a different object of relativity, Lucy critiques Neo-Whorfian relativity as the indexical parallel to Whorfian relativity. Lucy suggests that the object of Neo-Whorfian relativity, "the conscious construal of reality," is not clearly linked to the traditional concern of linguistic relativity: habitual thought (121). He states that Silverstein's "discussion as it stands bypasses the issues of when and why language becomes involved in thought and, therefore, exactly how such 'limits to awareness' operate to affect that involvement" (121). Lucy therefore concludes that "for Silverstein's arguments to play a crucial role in an account of the relation

of language and thought, [...] there needs to be a more direct application of them to Whorf's specific project" (126). Silverstein's theory, thus, is the application of Whorf's argument structure and his underlying semiotic mechanisms to the indexical realm of linguistic meaning, but it is an incomplete theory of how indexical meaning relates to thought.

\subsection{Neo-Whorfian Linguistic Relativity and Cul- ture}

Although Silverstein fails to provide a complete outline of the relation between language and thought in the indexical realm, he does provide an explicit account of the relationship between language and culture, a relationship that henceforth has remained implicit in linguistic relativity theorizing. To understand this relationship, 
it is necessary to first understand Silverstein's theory of culture. Though it is clear that Neo-Whorfian linguistic relativity rests on a theory of culture, Silverstein does not describe it in full in "Limits of Awareness." The theory is explicated, rather, in his papers "Cultural' Concepts and the Language-Culture Nexus" and "Indexical Orders and the Dialectics of the Sociolinguistic Life."

For Silverstein, cultures are "properties of populations of people who have come to be, by degrees, tightly or loosely bounded in respect of their groupness, their modes of cohering as a group" (Cultural Concepts 621). Silverstein argues that culture is linked to language through what he terms "cultural concepts," the "nexus" between language and culture. Cultural concepts are "people's [sociocentric] conceptualizations of their universe" (621). They exist at the ontological level of Thirdness and, consequently, are only "indirectly experienceable." Cultural concepts are composed of two features: (i) stereotypes $^{3}$, and (ii) the organization of the stereotypes into a structure. A STEREOTYPE is symbolic knowledge about an object in the world. The organization of stereotypes into structure is, as Silverstein states, "a kind of 'logic' of evaluational stances (good/bad; preferred/dispreferred; normal/deviant; etc)" (Indexical Orders 202). It organizes stereotypes in an ordered set of "serially structured value positions" (Silverstein, Cultural Concepts 632). Silverstein refers to this organization as "-onomic knowledge" or "knowledge schemata" (621). A cultural concept is represented schematically in Figure 2.5. Stereotypes are represented by lower-case letters $a-e$, and the structure of the culture concept is represented by the less-than symbol. Together, stereotypes and their organization form the mediating object between language and culture.

To illustrate a cultural concept and its features, consider a stereotype among some members of the Reed community: Lewis and Clark College is not a school for serious

\footnotetext{
${ }^{3}$ Silverstein sometimes uses the terms "stereotype" and "cultural concept" interchangeably. To distinguish between stereotypes and their organization within the cultural concept, I use the term STEREOTYPE to refer only to symbolic knowledge.
} 


\section{$a<b<c<d<e$}

Figure 2.5: A representation of Silverstein's cultural concept.

academics. This stereotype was presupposed in the comment of a Reed student while discussing a cognitive psychology lecture about memory. He commented that material is best remembered, that is, learned, if it is understood conceptually. To illustrate this point, he said, "This is why at Reed we write lots of essays, while at that other school, Lewis and Clark, they do lots of memorizing." In suggesting the pedagogical practices of Lewis and Clark are not focused on conceptual understanding, the comment presupposes the stereotype that Lewis and Clark is not academically rigorous. In the comparison of Lewis and Clark to Reed College, the second element of the cultural concept becomes evident: the relative organization of the stereotypes of Lewis and Clark and Reed. As is evident from the student's comment, academic rigor is valued in Reed culture and, consequently, is the basis for evaluational stances. The "structured value positions" of Lewis and Clark College and Reed College is thus that Lewis and Clark is less than Reed. The stereotypes of Lewis and Clark and Reed and their relative value form a cultural concept for Reed community members.

In "Cultural' Concepts and the Language-Culture Nexus," Silverstein argues that cultural concepts are signified iconically through "ritual" practice. More specifically, a /ritual/ signifies a //cultural concept// through diagrammaticity. Recall that a diagram, the second hypoicon in Peirce tripartite, means through the identity of relations between the Representamen and Object. Ritual, the practice through which the Representamen is constructed, has the identical relations as those within the cultural concept, the Object. The relations within the cultural concept are the organization of stereotypes into "serially structured value positions." It is this organization that 
is replicated in the ritual. Considered in another way, it may be said that [[ritual]] is a token of a //cultural concept//. At issue in the creation of any token are the relationships within the Representamen. As the Representamen, the token must have the same relationships as those within its type counterpart (the cultural concept, the Object). Thus, ritual practice is the realization of cultural concepts at the ontological level of Secondness.

So, what is ritual? It is, as Silverstein describes it, "verbal or nonverbal or, as is usually the case, a combination of multiple modalities of figuration played out in an orderly [...] space-time envelope of participation" (Cultural Concepts 626). That is, ritual is structured interaction. The structure within the ritual functions to define, or bind, the ritual as a discrete unit. As Silverstein states, it gives it "a semblance of formal plenitude-in-itself" (626). The binding of the ritual into a discrete unit allows the inter-relationships to emerge and, thus, allows the interaction to become a diagram. Semiotically, Silverstein argues that ritual is "a moving structure of indexical gestures toward the knowledge presupposed to be necessary to its own effectiveness in accomplishing something." That is to say, it is an icon-index. The icon lives in the relation between the cultural concept and the ritual. The cultural concept is "the knowledge presupposed to be necessary." The index lives in the relation between the ritual and the participants in the interaction. Because there is spacio-temporal contiguity between the Representamen, the ritual, and the participants, the Object, the ritual indexes the participants. The indexical nature of ritual is critical to its function. For speakers, the functional value of ritual practice lies in the potential it affords to manipulate one's position within the cultural concept. Because ritual is iconically related to cultural concepts and indexically related to speakers, it is able to mediate between speakers and cultural concepts. It is through mediation of ritual that speakers are able to affect their individual positions within the "ordering of cosmic conceptualizations [...], such as aspects of sacred or foundational knowledge, 
feeling, and belief"; that is, their position within cultural concepts.

To characterize ritual at a more concrete level, Silverstein provides the example of the Eucharist ritual. Silverstein describes the ritual below:

A person officiating at the service of the Eucharist, for example, bounds off a ritual space of objects at a table, an altar in the space-time of liturgical rite - wine poured from a cruet into a chalice, wafers or pieces of bread on a paten or ceremonial plate, both comestibles at a ritual table between him- or herself and a congregation of coparticipatory onlookers. He or she begins to tell the story of The Last Supper of Jesus and the Apostles, specifically quoting in the transposed here-and-now of the first-person figural narration and [...] gesturally holding up in turn the ritual objects: the congregants are informed that "This is my body," and instructed "Partake ye thereof!" and likewise "This is my blood," "Drink ye of it!" just as were the Apostles [...]. (Cultural Concepts 626)

The semiotic Object of the ritual is The Last Supper of Jesus and the Apostles, but, crucially, it is The Last Supper as it exists in "the cosmic order of sacred belief" (Silverstein, Cultural Concepts 626). The ritual constructs The Last Supper in the "here-and-now," at the ontological level of Secondness, by reproducing the (relevant) relationships. The relevant relationship, here, is the relationship between the officiant and the congregant. These two entities are related in the enacted ritual in the same way that Jesus and the Apostles are related in the cultural concept. Stated analogically, the officiant is to the congregant in the enacted ritual as Jesus is to the Apostles in the cultural concept. The ritual is bound by the physical space of the table. The diagrammatic relations within the ritual emerge with respect to this space. The participants are indexically related to "the cosmic order of sacred belief" through participation in the ritual. Thus, as an explicit ritual, the Eucharist service illustrates the means by which cultural concepts are realized in the realm of Secondness.

With the aim of defining the relationship between language and culture, Silverstein argues that some discursive interaction may be analyzed as ritual. That is, in discursive interaction, participants structure the discourse as a diagram of a cultural concept. The structuring, or as Silverstein terms it, "metricalization," is achieved in 
discourse through the organization of denotational text. The discourse is organized by a particular kind of denotation: DEIXIS ${ }^{4}$. Deictic forms denote one or more features of the speech situation. The "speech situation" includes the [[speakers]], the [[speech location]], and the [[speech time]]. Because deictic forms have spacio-temporal contiguity with these features, they are indexical. In the production of ritual, speakers use deictics to construct "dimensions of comparison" (Silverstein, Cultural Concepts 629). The "dimensions of comparison" correspond to the dimensions within cultural concepts. The stereotypical categories which are organized in the cultural concept correspond to the speakers themselves. Speakers construct these dimensions within the discourse through the use of spacial deictics, such as "here" and "there," and time deictics, such as "then" and "now" (628). Thus, as Silverstein argues, the discourse becomes "densely structured into pieces of information organized by 'placing' each with respect to other pieces of information" (629). It is "an emerging multidimensional array of repetition, comparison, and contrast" (628). In addition, speakers not only construct a dimension of comparison, but, through the indexical nature of deictics, they situate themselves within the dimension (629). Though less transparent than the Eucharist ritual, the features underlying "everyday conversation" as ritual are nonetheless the same as those in more explicit ritual: Relationships are constructed and participants are tied to those relationships through indexicality. In the case of "everyday conversation," the relationships are the social value positions within the dimensions of comparison, and speakers 'tie themselves' to the social value positions through deictics.

The indexical 'tying' of speakers to their stereotypes is the means by which ritual discourse fulfills its function: Speakers construct discourse into a ritual in order to align themselves with a particular stereotype within a cultural concept. As Silver-

\footnotetext{
4 "A term used in linguistic theory to subsume those features of language which refer directly to the personal, temporal or locational characteristics of the situation within which an utterance takes place, whose meaning is thus relative to that situation" (Crystal, Dictionary 127).
} 
stein states, "participants spatiotemporally manipulate signs of [stereotypes] in their uttered words" such that "an interaction is a dynamic of assuming and transforming relational stances" (Cultural Concepts 626, 631). Over time, the history of alignment and manipulation of these stereotypes can "entail [...] the causal (re)ordering of cosmic conceptualizations as figurally indexed, such as aspects of sacred or foundational knowledge, feeling, and belief, made figurally 'real' in the here-and-now of experienceable semiosis" (626). That is, the "serially structured value positions" within the cultural concept become reordered with time (632). Considered from a structuralist perspective, the set of "value positions," or stereotypes, is a system. Because meaning is emergent, the reordering of stereotypes fundamentally redefines them. The eventual redefinition of stereotypes forms a dialectic between cultural concepts and ritual interaction: cultural concepts are presupposed in discursive interaction, and, in turn, discursive interaction authorizes and redefines cultural concepts (632). As Silverstein formulates it, cultural concepts "come to life and are renewed in and by interaction" (632). In the ritual production of a cultural concept in the "here-and-now," thus, speakers semiotically work to redefine their place within the "cosmic" cultural concept. Critically, it is due to the diagrammatic nature of the ritual that speakers are able to redefine their relative position, their relationship, within the cultural concept.

In "Indexical Orders and the Dialectics of the Sociolinguistic Life," Silverstein outlines the place of metapragmatics within his theory of culture. He argues that metapragmatics is critical to the dialectic between cultural concepts and discursive interaction. To describe this dialectic, Silverstein introduces the notion of " $n$-th order indexical" (193). An $n$-th order indexical, Silverstein argues, "presupposes that the context in which it is normatively used has a schematization of some particular sort" (193). This notion fits neatly into the theory of culture proposed by Silverstein in "Cultural Concepts." To understand how it relates to the larger theory, consider Fig. 2.6. The diagram represents three semiotic objects: (i) discursive interaction 


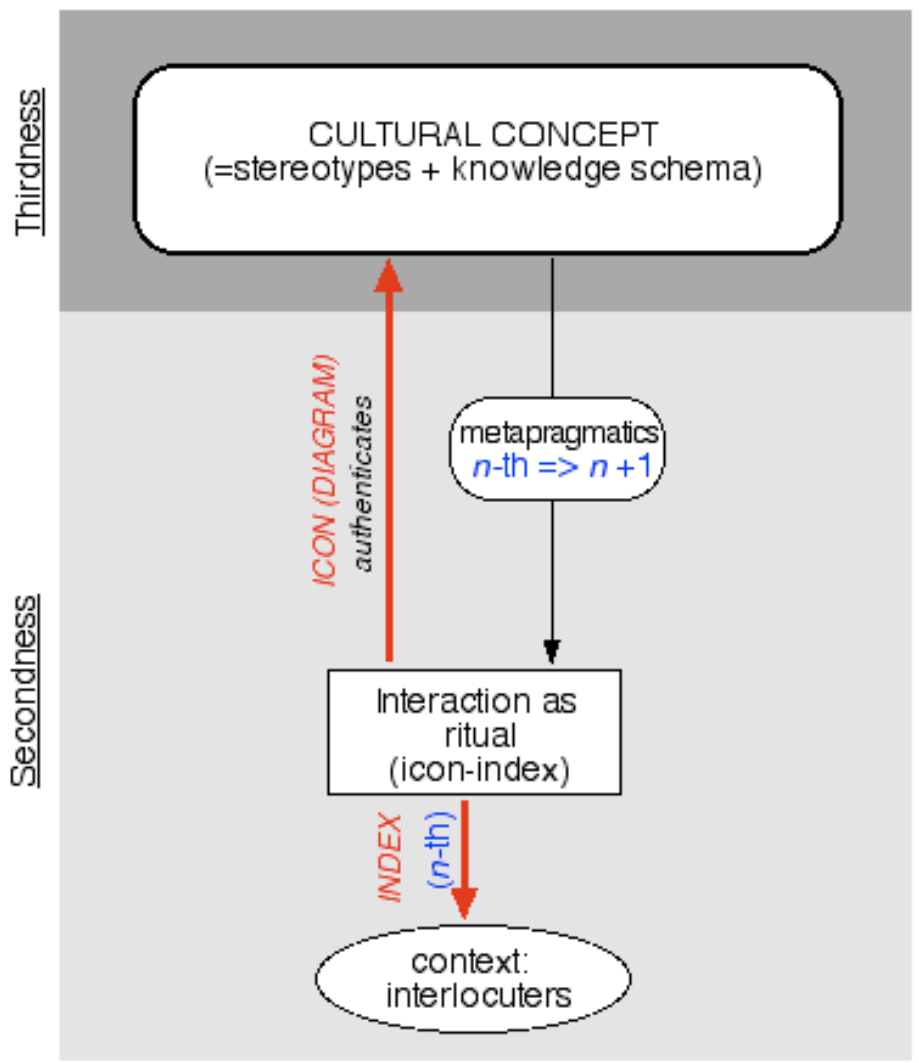

Figure 2.6: Silverstein's theory of culture as presented in "Cultural Concepts," and its relation to $n$-th order indexicality. 
(as ritual), (ii) speakers within the discursive interaction, and (iii) a cultural concept. The discursive interaction is the Representamen in two different sign relations. Speakers in the interaction are the Object in one of the sign relations, where the interaction and the speakers are related indexically ${ }^{5}$. The cultural concept is the Object in the second sign relation, where the cultural concept and the interaction are related iconically (diagrammatically). Thus, the " $n$-th order indexical" is the indexical relationship between the interaction and the speakers of the discursive interaction. The "schematization" of "the context in which it is normatively used" is, simply, the cultural concept (193).

Through a dialectic, Silverstein argues that a second order indexical (" $n+1$ ") is constructed. That is, the $n$-th order indexical is redefined. The process of its redefinition cannot be considered in sequential temporal order. Rather, the multiple processes that occur in its redefinition must be thought of as occurring on distinct semiotic planes. The $n$-th order indexical brings to mind in the interpreter a stereotype within a cultural concept. In the construction of the $n+1$ order indexical, this stereotype is re-interpreted in the context of the broader cultural concept. That is, its relationship within the cultural concept is considered. Because speakers are constantly negotiating and redefining the many stereotypes within a cultural concept, structuralist principles require that the interpretation of the the stereotype brought to mind by the $n$-th order indexical will change. The interpretation of the stereotype within the cultural concept considered as a whole is metapragmatics. Silverstein terms the cultural concept as it exists in the influence of metapragmatics as "ideology" (Indexical Orders 194). Silverstein states:

We must recognize the metapragmatic function $[\ldots]$ is ideologically saturated; it relates and, in its discourse mode even describes, explains, or rationalizes the pragmatics of language use [...] in terms of perhaps more

\footnotetext{
${ }^{5}$ Note that it is not always the case that speakers are the Object in $n$-th order indexicality. Rather, speakers are the Object only in cases of discursive interaction in which speakers manipulate their social value positions.
} 
fundamental frameworks, cultural agenda that bespeak human interests perspectivally caught up in social-institutional processes. In these terms such ideologically-informed metapragmatics shapes and, in the statistically measurable sense, biases our verbal and other interactional behavior; it endows otherwise mere behavior with indexical significance that can be "read" in relation to conventional norms. (Indexical Orders 196)

The "more fundamental frameworks" to which Silverstein refers are cultural concepts as ideological influences on metapragmatics.

Thus, the position of Silverstein's Neo-Whorfian claim within a theory of culture becomes clear: Relativity of metapragmatic awareness is relativity of awareness of the position of a stereotype within the cultural concept at large. Silverstein notes, however, that the denotationally explicit metapragmatic discourse at issue in "The Limits of Awareness," is only one type of "metapragmatic function" (Indexical Orders 196). "In general," he concludes, "the most robust and effective metapragmatic function is implicit, not denotationally explicit" (196). Nonetheless, Silverstein states in "Indexical Orders," "explicitly metapragmatic discourse is a sufficient indicator of metapragmatic function, and of metapragmatic intentionality" (196). But, crucially, as an indicator, it is predictably skewed by several semiotic properties of the discourse, the most of important of which, I argue, is the principle of unavoidable referentiality. 


\section{Chapter 3}

\section{A Reformulation of Whorfian Linguistic Relativity}

In Chapter II, I suggested that the common theory underlying Whorfian and NeoWhorfian relativity becomes less opaque when Neo-Whorfian thought is framed in terms of Silverstein's principle of unavoidable referentiality. By formulating Whorfian linguistic relativity as a type of metaphor, I argue here that Whorfian theory can also be framed in terms of the principle of unavoidable referentiality. Such a reformulation of Whorfian theory functions to further the parallels between Whorfian and Neo-Whorfian thought, and situate Whorfian linguistic relativity within a theory of culture.

\subsection{Formal Semiotic Grounding: Reformulated}

\subsubsection{Fashions of Speaking as Metaphorical Interpretations of Diagrammatic Classes}

Whorfian linguistic relativity is semiotically grounded in iconicity. In particular, it is grounded in two hypoicons within Peirce's tripartite: diagrams and metaphors. Icons 
are signs that mean through identity. The identity varies by hypoicon in its place in the sign relation and the nature of what is identified. The diagram, as discussed in Chapter I (pg. 17), is grounded in the Representamen. A diagram is characterized by the identity of indexical relations (real and potential) in the Representamen and the Object. A metaphor, by contrast, is grounded in the Interpretant. In a metaphor, it is Interpretants, rather than relations, that are in an identity relation. A metaphor is characterized by the identity of two Interpretants in two different IDEAS, where an idea is composed of a set of elemental Interpretants ${ }^{1}$. Consider, for example, the sentence [The dentist office is hell.]. The noun phrases [the dentist office] and [hell] correspond to two different sign relations with two different Interpretants. The sentence is a diagram that relates the two signs by suggesting an identity relation. Crucially, because the identity relation concerns elements within the two Interpretants, the sentence (the Representamen) cannot specify the shared element. For members of my sociocultural group, such a sentence might suggest that the $<$ the dentist office $>$ and $<$ hell $>$ share the element of $<$ unpleasantness $>$, but this is in no way specified within the Representamen. Rather, the Representamen merely suggests that there exists some shared element and the interpreter of the sign relation (here, the sentence) must determine what element that is.

In Chapter I, habitual thought is explained with reference to the Peircean diagramnamely, through the sociohistorical diagrammatic reasoning process. Metaphor, I argue here, is implicit in the argument of a sociohistorical diagrammatic reasoning process. To understand its role, consider the microcosm of reality represented in Fig. 3.1. From a perspective of realism, the world contains Objects with certain definite qualities. This microcosm of reality contains five Objects $[[\mathrm{A}]],[[\mathrm{B}]],[[\mathrm{C}]],[[\mathrm{D}]],[[\mathrm{E}]]$, each with three qualities (represented by lower case letters $|\mathrm{a}|-|\mathrm{g}|$ ). The schema does

\footnotetext{
${ }^{1}$ For the sake of clarity, I refer to the "elemental Interpretants" in an idea as ELEMENTS and I refer to a set of elements as an Interpretant, or idea. Notationally, elements are represented by italics. Note, however, that while a useful distinction for analysis, an element is qualitatively identical to an Interpretant/idea.
} 


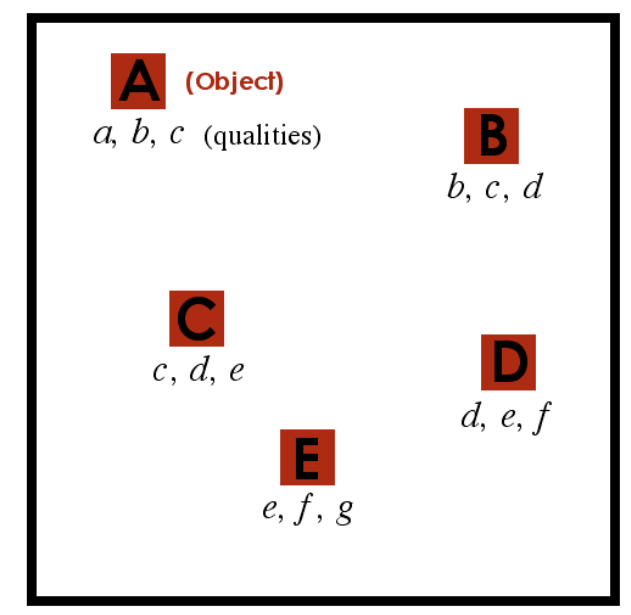

Figure 3.1: A realist representation of reality as containing Objects with certain definite qualities.

not commit to a way of organizing the ideas, rather it suggests multiple relationships between one idea and another. So, for example, Objects $[[\mathrm{C}]]$ and $[[\mathrm{B}]]$ could be categorized together because both share the qualities $|c|$ and $|d|$. Alternatively, $[[\mathrm{C}]]$ could be categorized with $[[\mathrm{D}]]$, to the exclusion of $[[\mathrm{B}]]$, because $[[\mathrm{C}]]$ and $[[\mathrm{D}]]$ share the quality $|\mathrm{e}|$. Analytically, then, there is motivation to organize these Objects in more than one way. Note, however, that the possibilities of organization are not unbounded: the set of possible categories is constrained by experiential qualities. It might be difficult, for example, to identify a basis for categorizing the ideas of "throwing" and "book" together.

One function of language is to symbolically denote Objects in the world. Language cannot, however, denote them in the same way that is intended by the schema abovethat is, in a way that avoids categorization. Rather, as a system of symbols, language must commit to a single system of categorization; it must categorize Objects by some criterion of similarity. Because there is more than one way to categorize Objects based on qualities, different languages categorize in different ways. Crucially, as language interfaces with reality, it mediates between interpreters and Objects in the 


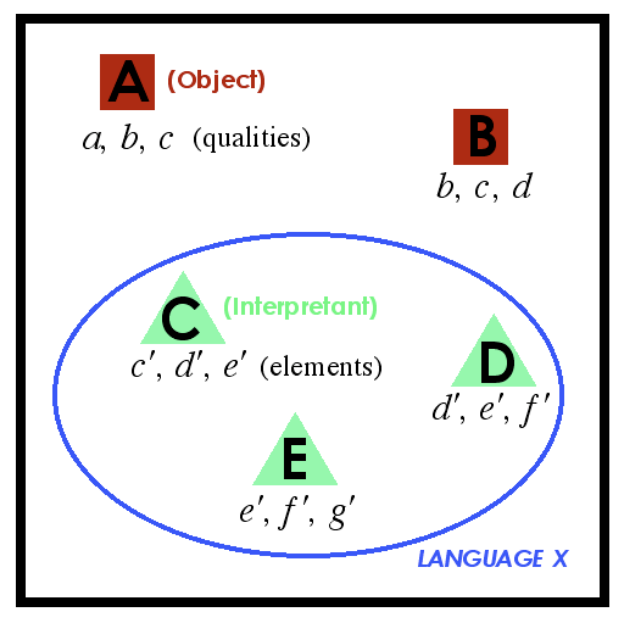

Figure 3.2: Language as a system of organizing reality. Language interfaces reality by "encircling," or categorizing, Objects based on some criterion of similarity. Crucially, however, it is not Objects which language categorizes, but Interpretants. The criterion of similarity for a categorization is thus an element within the Interpretant. Elements of Interpretants are distinguished from qualities by prime notation.

world. Thus, the entities which language "organizes" are Interpretants or ideas, rather than Objects, and the criterion of similarity motivating the organization is based on elements within those Interpretants. Elements of Interpretants are imperfect copies (images) of qualities of Objects, which are skewed by socioculture. In language $\mathbf{X}$ in Fig. 3.2, ideas $\langle\mathrm{C}>,<\mathrm{D}>$ and $<\mathrm{E}>$ are categorized together because they share the element $\langle e\rangle$, but another language might have justifiably categorized $\langle\mathrm{B}\rangle,\langle\mathrm{C}\rangle$, and $\langle\mathrm{D}>$ together based on the common element $<d>$. Language organizes ideas by means of grammatical categories; that is, by means of diagrammatic classes. A grammatical class, as was argued in Chapter I (pg. 12), is a set of morphemes with the same potential for indexical relations with other linguistic units at the same 'level' of structure (here, words). Put another way, it is a set of morphemes with the potential to fit in the same set of syntagmatic frames. Language categorizes ideas as similar and dissimilar by grouping morphemes according to shared potential syntagmatic frames. That is, with reference to Fig. 3.2, language "encircles" ideas $<\mathrm{C}>,<\mathrm{D}>$, and $<\mathrm{E}>$, 
to the exclusion of $\langle\mathrm{A}>$ and $<\mathrm{B}>$, by means of grammatical categories.

In "Iconicity, Hypoiconicity," Tony Jappy argues that the Representamen of a metaphor is formally indistinguishable from that of a diagram. This is due to the semiotic grounding of metaphor in the Interpretant. The Interpretant, by definition, does not exist in the existential realm. Nonetheless, as Jappy argues, "all forms of communication [...] must be channeled so to speak through an existential medium." Thus, in the existential realm, the distinguishing feature of metaphor cannot be represented and, consequently, diagrams and metaphors become formally identically. This formal ambiguity has the significant consequence that speakers may interpret diagrams in language either diagrammatically or metaphorically. Consider for example the sentence [Sasha is a clown]. This could be interpreted diagrammatically as a relationship of identity of the Interpretants $<$ Sasha $>$ and $<$ clown $>$, say because Sasha dressed up as a clown for Halloween. Alternatively, under a metaphorical interpretation, one could understand this sentence to mean that $<$ Sasha $>$, like a $<$ clown $>$, is silly. That is, the Interpretants $<$ Sasha $>$ and $<$ clown $>$ share the element of $<$ silliness $>$. Both interpretations, from a formal perspective, are equally motivated. Note, however, that not all diagrams have the potential for metaphorical interpretation. Rather, it is a subset of diagrams, namely, those that suggest an identity relation, which are formally identical to metaphors.

It is the formal identity of the Representamena of a metaphor and a diagram that, I argue, enables the sociohistorical diagrammatic reasoning process. As I argued in Chapter I (pg. 18), the sociohistorical diagrammatic reasoning is the implicit reasoning of a socioculture that, over time, produces relativity at the level of habitual thought. Briefly, the process occurs when two ideas share a diagrammatic class, such as words of space and time in English, such that speakers talk about one in the same way they talk about the other. Over the course of a history of a socioculture, this common way of speaking about two ideas suggests to speakers that 
the two ideas are in fact the same; that is, that they sharing some element in common. Speakers most likely are not able to identify this element, but they nonetheless assume such an element to exist. The understanding of a shared element between two Interpretants characterizes habitual thought. Semiotically, this conclusion to the diagrammatic reasoning process is a metaphorical interpretation of a diagrammatic class. Language organizes morphemes into diagrammatic classes, because it must as a system of symbols, and because the structure of a diagram is indistinguishable from a metaphor, speakers tend to interpret the semiotically ambiguous structure of language as metaphor rather than as diagram in the eventual conclusion to the sociohistorical diagrammatic reasoning process. That is, speakers assume that Interpretants, whose Representamena share a diagrammatic class, also share a common element. Relativity of habitual thought, therefore, is the product of the ambiguous semiotic structure of diagrammatic classes.

To illustrate the place of metaphor within the sociohistorical diagrammatic reasoning process, consider Fig. 3.3, a revised version of the representation of the sociohistorical diagrammatic reasoning process from Chapter I (Fig. 1.4). The right section of the diagram represents the sign relations of [cup] and [pound] and the consequential process of sociohistorical diagrammatic reasoning. As was noted in Chapter I, however, the two Representamena [cup] and [pound] do not have identical Interpretants as the diagram suggests. Rather, the conclusion to the sociohistorical diagrammatic reasoning process is the salience in habitual thought that there exists an element within each of the two Interpretants that is identical. That is to say, the conclusion is a metaphorical interpretation of [cup] and [pound]. To understand exactly what is at issue in the Interpretant of a metaphor, consider Fig. 3.3 in conjunction with Fig. 3.1. Assume that [[cup]] corresponds to Object [[C]] in Fig. 3.1 and $[[$ pound $]]$ corresponds to Object $[[\mathrm{D}]]$. The Object $[[\operatorname{cup}]]$ has the qualities $|c|$, $|\mathrm{d}|$ and $|\mathrm{e}|$ and the Object [[pound]] has the qualities $|\mathrm{d}|,|\mathrm{e}|$ and $|\mathrm{f}|$. The distinct 


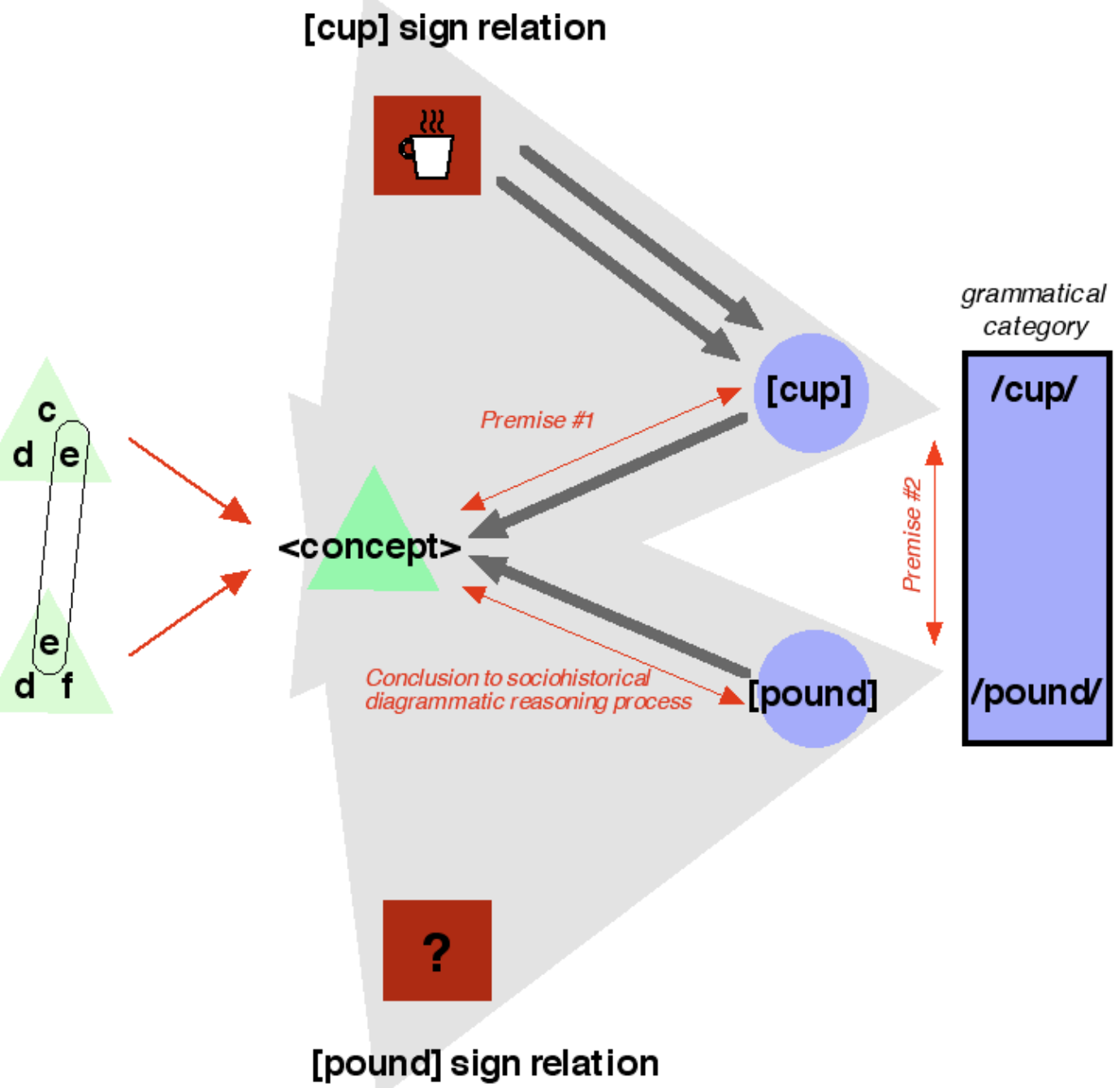

Figure 3.3: A representation of the implicit role of metaphor within the sociohistorical diagrammatic reasoning process, where [[cup]] corresponds to Object [[C]] in Fig. 3.1 and [[pound]] corresponds to Object [[D]]. 
Interpretants of $<$ cup $>$ and $<$ pound $>$ contain elements which are imperfect images of these qualities. Language $\mathbf{X}$, like English, happens to group the Representamena [cup] and [pound] together into a diagrammatic class. Crucially, this grouping into a common diagrammatic class suggests to speakers that the relevant criterion for similarity is an element which they have in common in their Interpretants, here element $\langle e\rangle$. It is thus with respect to element $\langle e\rangle$, whatever element that might be, that speakers think of [[cup]] and [[pound]] as the 'same' in habitual thought.

It is thus clear that the formal structure of a diagram allows for an interpretation as either a diagram or a metaphor and that, in the case of the sociohistorical diagrammatic reasoning process, speakers show a tendency toward the latter. Why is this the case? Silverstein suggests this tendency is the product of what Peirce terms ABDuctive ReAsoning (Whorfianism 104). Below, Peirce describes abductive reasoning:

Upon finding himself confronted with a phenomenon unlike what he would have expected under the circumstances, he looks over its features and notices some remarkable character or relation among them, which he at once recognizes as being characteristic of some conception with which his mind is already stored, so that a theory is suggested which would explain (that is, render necessary) that which is surprising in the phenomena. (Peirce, Commens, CP 2.776)

More concisely, abductive reasoning is the act of "examining a mass of facts and in allowing these facts to suggest a theory" (Peirce, Commens, CP 8.209). Faced with the structural facts of language, speakers aim to untangle them in the most economical way. This is done by "examining the mass of facts" of the language structure, namely the grouping of morphemes into grammatical categories, and "allowing these facts to suggest a theory." The theory that seems to be most plausible to speakers is that certain ideas in language are categorized together because they are in fact similar; because they share an element. Speakers 'error,' so to speak, then, is their failure to recognize that their interpretation of the structure of language as metaphor is a 
mere hypothesis. That is, that the consequences that fall from this hypothesis are the product of the unique structure of their language. Thus, they fail to recognize that, though a speaker of a different language would likely follow the same path of abductive reasoning, this reasoning would lead to a different conclusion about the organization of the world. Speakers' metaphorical interpretations of diagrammatic classes, then, are the product of abductive reasoning. Abductive reasoning can thus be considered the motivating force behind the conclusion to the sociohistorical diagrammatic reasoning process.

Whorf's central claim, in my terms, is that speakers are not aware of their metaphorical interpretations of diagrammatic classes produced by the sociohistorical diagrammatic reasoning process. This limited awareness can be explained, I argue, with reference to Silverstein's principle of unavoidable referentiality. As posited in the realm of Neo-Whorfian linguistic relativity (pg. 28), this principle states, broadly, that speakers will be more aware of linguistic meaning when its Representamen coincides with a form with denotational value. A corollary to this principle, thus, is that speakers will be less aware of linguistic meaning when its Representamen does not coincide with a form with denotational value. It is this corollary to Silverstein's principle, I suggest, that is relevant to Whorfian linguistic relativity. The Representamen at issue, in the case of Whorfian relativity, is a diagram. The diagram, a grammatical category in language structure, is constructed below the level of denotation: grammatical categories are formed, that is, diagrams are constructed, by potential structural relationships at the level of langue. With an understanding of Whorfian linguistic relativity as metaphorical interpretations of diagrams below the level of denotation, speakers' limited awareness of their metaphorical interpretation becomes a predictable consequence of the corollary to Silverstein's principle. 


\subsubsection{Metaphorical Interpretations within Poetic Language: The Analog to Metaphorical Interpretations of Gram- matical Categories at the Level of Reference and Pred- ication}

Crucially, if we are to accept the corollary to Silverstein's principle as the explanation of Whorfian linguistic relativity, we must consider evidence for the principle itself within the symbolic domain. That is, we must consider evidence for the claim that speakers will be more aware of linguistic meaning when its Representamen coincides with a form of denotational value. In the realm of symbolic meaning, this principle takes the form: Speakers will be more aware of a metaphorical interpretation when the diagrammatic Representamen is constructed at the level of reference and predication. There exists evidence for this prediction, I argue, within poetic language. The analog to grammatical categories at the level of reference and predication is diagrammatic forms within poetic language, which speakers tend to interpret metaphorically. I suggest that speakers tend to be highly aware of their metaphorical interpretation of these diagrammatic forms, as such, within poetic language. Therefore, it seems that, within the realm of Whorfian linguistic relativity, awareness of a metaphorical interpretation depends on the construction of the diagrammatic Representamen at the level of reference and predication. Thus, I conclude, the pattern of speakers' awareness of metaphorical interpretations can be explained by Silverstein's principle of unavoidable referentiality.

Paul Friedrich defines POETIC LANGUAGe to be "all parts of a language system that exemplify a figure" (Parallax 24). Friedrich argues that "poetic language is actualized in all domains of life, even the logician's study, and is common in cafeterias, bars, streets, at kitchen tables and conveyor belts - wherever one argues, persuades, seduces, reports, creates rapport or otherwise communicates - and particularly in 
moments of playfulness, humor, trauma, crisis, and strong emotion" (24). Thus, concludes Friedrich, "the reality is not poetry versus nonpoetry but more poetry versus less poetry" (24). The "poet" properly speaking, then, "alchemizes through a special process from the prodigious skills that are mastered by every native speaker and used by everyone every day" (26). Poetic language exists at the level of reference and predication; at the level of pointing to things and making statements about them. It is a subset of language at the level of reference and predication, but it is nonetheless a large subset. Our concern with poetic language, as, critically, a type of language at the level of reference and predication, is thus not a deviant use of language, but rather a broad phenomenon occurring in everyday discourse.

Metaphor at the level of discourse, argues Friedrich, is a category of poetic language. In particular, he argues that it is a subtype of one of at least five macrotropes within poetic language (Polytropy 43). A TROPE is "anything that a poet, politician, pundit, or Everyman uses or employs - whether intentionally or unintentionally - to create poetic texture and effect, poetical meanings and poetic integration" (26). The five macrotropes compose the "total tropological system" of poetic language (43). Friedrich suggests this system be thought of as the "horizontal continua" of tropes (39). Along these continua, a metaphor is a subtype of the "analogical" macrotrope. The analogical macrotrope "is based partly on the fact that any one thing in the universe resembles any other thing in more than one way: a sweater and a socket both produce electricity" (37). The horizontal continuum of macrotropes is crossed with the "vertical continua" (39). In the case of the analogical macrotrope, the vertical continua concerns degrees of similarity (40). Friedrich identifies the end of extreme similarity as tautology, "where $\mathrm{X}=\mathrm{X}$, yellow is yellow, and so forth" (40). Below, Friedrich describes the opposite end of the continuum:

Any two things, since any two things, acts, words, or whatever in the universe will share features. The inevitable comparability of any two things is an interesting complement to the categorical, overall non-identity 
of any two things (outside mathematics). (40)

Metaphor is positioned somewhere in the middle of these two extremes. It is characterized, in particular, as instances of analogical trope in which "the similitude is neither too great nor too small (as determined by cultural attitudes)" (40). In sum, then, poetic metaphor may be characterized as (i) a type of poetic language, which exists at the level of reference and predication, and (ii) a culturally appropriate similarity between two Interpretants.

Friedrich's definition of poetic metaphor concerns, implicitly, the Interpretant of the poetic metaphor: the degree of similarity between two Interpretants is determined by the "culture attitudes" of the interpreter, and cannot be inferred from the Representamen alone. This characterization is consistent with the Peircean understanding that metaphor is grounded in the Interpretant. Despite this grounding in the Interpretant, the Representamen of the poetic metaphor, as for all metaphor under the Peircean conception, is a significant part of the theory. It is significant because the Representamen of a metaphor must be of a particular form. Namely, it must be of a form that suggests that two signs are related by identity. This form, it just so happens, is indistinguishable from the Representamen of a diagram.

Beginning with Aristotle, the appropriate Representamen for analysis of the poetic metaphor has been argued to be the isolated word. In the Poetics, Aristotle provides the following definition of metaphor: "Metaphor consists in giving the thing a name that belongs to something else" (qtd. in Ricoeur 13). In The Rule of Metaphor, Paul Ricoeur argues that such a definition "suggests that metaphor is something that happens to the noun" (16). It suggests, furthermore, a theory of metaphor grounded in "the idea of substitution for an absent but available ordinary word" (20). It is on this basis that Aristotelian approach to metaphor has been termed "substitution theory" (4). Ricoeur provides a strong critique of this approach: He states that "for if the metaphorical term is really a substituted term, it carries no new information, 
since the absent term (if one exists) can be brought back in; and if there is no information conveyed, then metaphor has only ornamental, decorative value" (20). This critique can be thought of in terms of predicate logic. Consider the sentence [Sasha is wise]. This sentence is composed of a property, the 'wise' property, and an entity in the world, [[Sasha]]. The 'wise' property is a predicate that takes one argument, namely a subject. It can be represented as a function $\mathrm{W}(\mathrm{x})$, in which ' $\mathrm{x}$ ' is its subject argument. The sentence can thus be represented as W(s), where 's' denotes [[Sasha]]. A metaphoric reformulation of this sentence might be [Sasha is a turtle] (in cultures in which a turtle is associated with wisdom). The Representamen of the second sentence is formed by substituting the word [wise] in the first sentence with [turtle]. To compare these two sentences in predicate logic, let the 'turtle' property be denoted as $\mathrm{T}(\mathrm{x})$. With reference to these two sentences, Aristotle's claim is that $\mathrm{W}(\mathrm{s})$ is equivalent to $\mathrm{T}(\mathrm{s})$; that to be wise is the same as to be a turtle. Clearly, such a claim is false. Because the metaphor is grounded in the Interpretant, the relevant element of a turtle in the metaphor is left undetermined. Thus, one might justifiably interpret the sentence [Sasha is a turtle] to mean $<$ Sasha is slow $>$ rather than $<$ Sasha is wise $>$. Aristotle's error, then, is to ground his analysis of metaphor in the Object: to say that the Object of the sign $\mathrm{W}(\mathrm{x})$ is equivalent to the Object of sign $\mathrm{T}(\mathrm{x})$ is false, but to say that an element within the Interpretant of $\mathrm{W}(\mathrm{x})$ is the same as an element within the Interpretant of $\mathrm{T}(\mathrm{x})$ may be true (for a given Interpreter). Poetic metaphor thus is not merely "ornamental" and "decorative" because it suggests something - an identity relation between two elements within two Interpretants - that is not immediately obvious. It is in this sense that poetic metaphor provides "new information" and is therefore incompatible with Aristotle's definition.

Ricoeur proposes an alternative to Aristotle's theory by suggesting that the appropriate unit of analysis for poetic metaphor, that is, the appropriate Representamen, is not the word, but "the metaphorical statement" (65). The relevant relationship 
in the metaphor is not, as Aristotle suggests, between two nouns such as [wise] and [turtle]. Rather, the relevant relationship in the Representamen is, between [Sasha] and [turtle], in the case of the second sentence above. The element of being wise becomes relevant only in the Interpretant. For a metaphor, then, the Representamen must relate [Sasha] and [turtle]. The Representamen that relates [Sasha] and [turtle] is at the level of statement. Note that, as a form that relates two signs, the metaphoric statement is a diagram. Based on this analysis, Ricoeur argues that the statement is "the carrier of 'complete and finished meaning' (according to Fontanier's own expression), in the production of metaphorical meaning" (65). He explains that this is because "we are not dealing any longer with simple transfer of words, but with a commerce between thoughts"; a commerce between Interpretants (80).

In The Philosophy of Rhetoric, I.A. Richards highlights the significance of Ricoeur's statement approach to poetic metaphor:

To account for understanding and misunderstanding, to study the efficiency of language and its conditions, we have to renounce, for a while, the view that words just have their meanings and that what a discourse does is to be explained as a composition of these meanings - as a wall can be represented as a composition of its bricks. We have to shift the focus of our analysis and attempt a deeper and more minute grasp and try to take account of the structures of the smallest discussable units of meaning and the ways in which these vary as they are put with other units. Bricks, for all practical purposes, hardly mind what other things they are put with. Meanings mind intensely - more indeed than any other sort of things. It is the peculiarity of meanings that they do so mind their company; that is in part what we mean by calling them meanings! (10-11)

Richards' brick analogy suggests that the meaning of a metaphor can be determined only by considering the individual meanings in context; the relationship between the meanings. That is, the relevant element in the Interpretant emerges only through the comparison with a second Interpretant. A brick's identity, in contrast, is insensitive to its context. Crucially, it is only through the analysis of the whole statement that a consideration of this context to the individual meanings can occur. Thus, by 
establishing the "metaphoric statement" as the unit of analysis of poetic metaphor, Ricoeur is able to ground his theory in the Interpretant, rather than the Representamen. Through this revision to Aristotle's theory, Ricoeur produces a theory of poetic metaphor that is consistent with Peirce's more general theory of metaphor.

For our purposes, then, Friedrich and Ricoeur suggest two important characteristics of poetic metaphor: (i) poetic metaphor is 'metaphor' in the Peircean sense, and (ii) it is constructed at the level of reference and predication. For Peirce, metaphor is the identity of two elements in different Interpretants (as defined previously on pg. 48). By arguing that poetic metaphor is determined with respect to "cultural attitudes," Friedrich, implicitly, grounds his theory of poetic metaphor in the Interpretant of the Peircean sign relation. Similarly, Ricoeur makes it clear that his theory is grounded in the Interpretant through his discussion of poetic metaphor as "a commerce between thoughts." Richards' emphasis on context within poetic metaphor suggests that the Interpretants of the component signs are not context independent, but rather depend on context to make a particular element salient. The Peircean metaphor is characterized, further, by a Representamen that is a diagram. Because the function of the statement is to relate signs, Ricoeur's claim that the statement is the unit of the poetic metaphor is, in effect, a claim that the Representamen of poetic metaphor is a diagram. With respect to the second characteristic, Ricoeur's approach to poetic metaphor at the level of the statement suggests that poetic metaphor is constructed at the level of reference and predication: a statement, or proposition, is by definition, the linguistic unit of reference and prediction. Ricoeur, in fact, makes an explicit claim about the predicative nature of poetic metaphor: "metaphor is a kind of 'attribution' requiring a 'subject' and a 'modifier'" (95). As a type of Peircean metaphor, poetic metaphor may thus be thought of as the analog at the level of reference and predication to metaphoric interpretations of grammatical structure.

However, as the analog to metaphorical interpretations of grammatical structure 
at the level of reference and predication, poetic metaphor is distinguished by an important feature: Unlike metaphorical interpretations of grammatical structure, speakers tend to be aware of their metaphorical interpretations of poetic metaphor. Consider, for example, the following lines from Shakespeare's As You Like It:

All the world's a stage,/And all the men and women merely players.

Or, the following quote from Moby-Dick:

Yes, the world's a ship on its passage out, and not a voyage complete; and the pulpit is its prow. (57)

In both examples, the sentence constructs a diagram relating [the world] and a second form, [stage], in the case of the first metaphor, and [ship] in the case of the second. The diagram is constructed with a form of the equative copula 'is' ${ }^{2}$. The degree to which speakers are aware of their metaphorical interpretations of these diagrams is an empirical question. Nonetheless, I claim, from the basis of anecdotal evidence, that speakers are aware that Shakespeare's line means that $<$ the world $>$ is like $<$ a stage $>$ in some sense. Or, in the case of the second sentence, that $<$ the world $>$

\footnotetext{
${ }^{2}$ Of course, metaphor in poetic language need not take the form $\mathrm{X}=\mathrm{Y}$ in order to be interpreted as metaphor. In fact, most uses of metaphor in poetic language are not of this form. The metaphor may take the form of $\mathrm{X}$ 'is like' $\mathrm{Y}$, as is the case in the following quote from Hamlet:

Hamlet: Do you see yonder cloud that's almost in shape of a camel?

Polonius: By th' Mass, and 'tis like a camel, indeed.

Hamlet: Methinks it is like a weasel. (3.2.368-370)

Most frequently, however, there is no formal marker that functions independently to indicate the relationship between the two forms in the diagrammatic relationship. This is the case in the following lines from "My Fancy," a poem by Lewis Carroll:

She has the bear's ethereal grace,

The bland hyena's laugh,

The footstep of the elephant,

The neck of the giraffe. (248)

Here, [she] is in a diagrammatic relationship with [bear], [hyena], [elephant], and [giraffe]. These diagrams are interpreted metaphorically by considering the element in common between $<$ she $>$ and the four animals. In these particular metaphors, Carroll provides a suggestion of the relevant elements: $\langle$ grace $>,<$ laugh $>,<$ footstep $>$, and $<$ neck $>$, respectively.
} 
is like <a ship $>$ in some sense. Crucially, in Peircean terms, the 'sense' in which the two are similar is an element in the Interpretants. That is, speakers understand there to be an identical element in the Interpretants $<$ the world $>$ and $<$ a stage $>$ and the Interpretants $<$ the world $>$ and $<$ a ship $>$. In a parallel analysis of grammatical categories, consider, again, the grammatical category containing the forms [pound] and [cup]. The grammatical category constructs a diagrammatic relationship between the forms [pound] and [cup]. Whorf's claim is that speakers, as a result of fashions of speaking, think of $[[$ pound $]]$ as like [[cup]] in some important sense in their habitual thought. That is, that speakers interpret the diagram of the grammatical category as metaphor. Crucially, speakers are not aware of this metaphorical interpretation. They are not aware that $<$ pound $>$ and $<$ cup $>$ are alike only in a particular, arbitrary sense; with respect to a particular element. In sum, then, speakers tend to interpret both grammatical structure, which is a diagram constructed below the level of reference and predication, and poetic metaphor, which is a diagram constructed at the level of reference and predication, as metaphor. In the case of the latter, but not the former, speakers are aware of their interpretation as metaphorical.

Thus, poetic metaphor has two characteristics which differ from that of the metaphorical interpretation of grammatical categories (i) its construction at the level of reference and predication, and (ii) its tendency to be within speaker awareness. My central argument is that these two characteristics of poetic metaphor are related: Speakers are aware of their metaphorical interpretations of poetic language because poetic metaphor is constructed at the level of reference and predication. This claim results from the application of Silverstein's principle of unavoidable referentiality to the domain of Whorfian linguistic relativity. This claim suggests that awareness of the 'thought grooves' of language in the case of both Whorfian and Neo-Whorfian linguistic relativity is dependent on the extent to which the meaning at issue coincides with a form with denotational value. In the case of Neo-Whorfian linguistic relativity, 
the form at issue is a pragmatic marker. In the case of Whorfian linguistic relativity, the form at issue is a diagram. The diagram coincides with a form with denotational value when it is a statement of poetic language.

\subsubsection{Fashions of Speaking and Poetic Metaphor}

I have argued thus far that Whorfian linguistic relativity is the domain of the corollary to the principle of unavoidable referentiality, and that poetic metaphor is the domain of the principle of unavoidable referentiality itself. However, there is an area of intersection between the two domains: Whorfian fashions of speaking (pg. 14). Fashions of speaking are metaphoric tropes in poetic language. Fashions of speaking do not, however, fit the pattern predicted by the principle of unavoidable referentiality: they are metaphorical interpretations at the level of reference and predication for which speakers not aware. Fashions of speaking, I argue, are a special type of poetic language. Namely, they are the set of metaphors in poetic language which are suggested by the structure of the language and, as such, are subject to the sociohistorical diagrammatic reasoning process (pg. 18). Fashions of speaking, as defined with respect to the present terms, are the realization of the diagram of the grammatical category at the level of reference and predication. At the first stage in the process, speakers are aware of their metaphorical interpretation of the statement, as predicted by the principle of unavoidable referentiality. Over time, however, the sociohistorical diagrammatic reasoning process demotes these statements from the plane of awareness, such that they no longer are interpreted consciously as metaphor. In the context of Fontanier, Ricoeur discusses this process by which poetic metaphor is demoted:

[...] all usage [of language] tends to become habitual, and metaphor tends to resemble catachresis. The metaphor still remains a figure, for its purpose is not to fill a gap in signs. However, it appears in a more and more fixed and standardized fashion, and, in this sense, can be said 'to be part of the foundation of language - that is, it begins to act like literal 
meaning. (62)

Metaphorical statements which "act like literal meaning" are metaphorical statements which, to put it another way, are not recognized by speakers as metaphorical interpretations. Fashions of speaking thus are a special case of poetic language, whose status below the plane of awareness can be explained with reference to the sociohistorical diagrammatic reasoning process.

Notably, metaphor in poetic language that exists above the plane of awareness is not merely the set of 'metaphorical ways of talking' suggested by the structure of one's language. That is, it is not merely the set of metaphorical statements at the beginning stage of the sociohistorical diagrammatic reasoning process. Rather, metaphorical statements exist in language which are not suggested by the structure of language. These 'novel' metaphors are the product of the imagination of speakers. For Friedrich, imagination is a critical piece to his theory of poetic language. As a preliminary axiom to his theory, he states: "I assume that the imagination of the unique individual $[\ldots]$ is a central reality, perhaps the central reality of language and of its actualization in speech" (Parallax 16). He defines imagination to be "the processes by which individuals integrate knowledge, perceptions, and emotions in some creative way which draws on their energies in order that they may enter into new mental states or new relations with their milieu" (18). Crucially, that is, the imagination produces "new relations with their milieu" which are not already suggested by language structure. As Friedrich states, the imagination produces poetic language in which "all the usual levels and compartments of language are partly altered, even merged and broken, in ways that suggest the novel, the primordial, or the chaotic" (22). Because language suggests one possible organization of the world, Friedrich suggests that "language can be seen as infinitude of used poems waiting to be molded into new realities as one determines and fails to determine, the degree and direction to which one will be influenced by them" (33). Thus, the structure of language is 
suggestive but not deterministic in a conceptualization of the world. Consequently, metaphor within poetic language contains both (i) realizations of the organization of the world as suggested by grammatical categories, and (ii) novel organizations produced from speakers' imaginations.

In conclusion, then, poetic metaphor, as the analog to grammatical categories at the level or reference and predication, provides evidence for the principle of unavoidable referentiality within the symbolic domain of linguistic relativity. Fashions of speaking are a special case of poetic language which begin as conscious metaphor but are demoted from the plane of awareness through the sociohistorical diagrammatic reasoning process. Furthermore, I argue that poetic language is not merely fashions of speaking in their beginning stages, but rather that the imagination produces metaphors which are not suggested by language structure. Thus, there is evidence for both the corollary to Silverstein's principle and the principle itself within the symbolic domain of linguistic relativity: speakers tend to be less aware of metaphorical interpretations constructed below the level of reference and predication (grammatical categories) and more aware of metaphorical interpretations constructed at the level of reference and predication (poetic metaphor). I therefore conclude that both NeoWhorfian and Whorfian linguistic relativity can be framed in terms of the principle of unavoidable referentiality.

\subsection{Whorfian Linguistic Relativity and Culture}

By framing Whorfian linguistic relativity in terms of the principle of unavoidable referentiality, Section 3.1.2 presents Whorfian linguistic relativity in parallel terms to those of Neo-Whorfian linguistic relativity. The common framework of Whorfian and Neo-Whorfian thought allows the theoretical advancements within each domain to be applied to the other. Most significantly, it is possible to consider how Whor- 
fian linguistic relativity fits into the theory of culture defined with respect to the Neo-Whorfian domain in Chapter II (pg. 37). This is the aim of the present section. Toward this end, I first address the relationship between poetic metaphor, specifically, and culture. Naomi Quinn's paper "The Cultural Basis of Metaphor," a response to recent work on (poetic) metaphor by cognitive linguists, is the primary text considered. With Quinn's work as a starting point, Whorfian linguistic relativity is then situated within the broader theory of culture presented in the Neo-Whorfian domain. It is by situating both theories within a single theory of culture that the profit of their common framework is fully realized.

Much of the recent work on metaphor has placed culturally constituted meaning at the periphery. Theorists in the tradition of cognitive linguistics argue that metaphor is a "mapping between conceptual domains in the human mind" (Croft and Cruse 194). A metaphor, they argue, involves "a SOURCE DOMAIn, the source of the literal meaning of the metaphorical expression, and a TARGET DOMAIN, the domain of the experience actually being described by the metaphor" (55). In the metaphor, /Her anger boiled over/, for example, the 'heat of a fluid,' as indexed by /boiled/, is the source domain. To form the metaphor, the source domain is mapped onto the target domain 'anger' (196). Crucially, cognitive linguists argue that metaphors such as this are "the result of a special process for arriving at, or construing, a meaning" (194). Plainly, that is, metaphors make new meaning. Meaning is construed by considering the entailment relations that follow from a metaphor: If $\mathrm{x}$ and $\mathrm{y}$ are related in a certain way in the source domain and the source domain is like the target domain, then $\mathrm{x}$ and $\mathrm{y}$ of the target domain must be related in the same way as in the source domain. In this way, metaphor functions to structure understanding of the target domain that did not previously exist. For cognitive linguistics, thus, metaphors are "the manifestation of a conceptual mapping between two semantic domains" (198). Their function is to create new understanding. 
Note that there is motivation from a Peircean perspective for cognitive linguists' concern with metaphor: Since metaphor is grounded in the Interpretant, it is reasonable to consider the relationship between metaphor and thought. Their theory, however, becomes problematic when it fails to consider factors which influence the Interpretant, the most important of which is culture. It is on this basis that Quinn critiques the theory of metaphor proposed by cognitive linguistics. Her aim is, as she states, "to retake some of the territory cognitive semanticists have claimed for metaphor and claim it instead for the phenomenon [she studies]-culture" (56).

Quinn "retakes" metaphor by arguing that cultural knowledge is logically prior to all metaphorical interpretations. She defines culture as "the shared understandings that people hold and that are sometimes, but not always, realized, stored, and transmitted in their language" (57). Her central argument is that the source domain in a metaphor is not selected from the basis of universal human tendencies, as cognitive linguists suggest, but rather is motivated by a cultural understanding of the target domain. In Peircean terms, her claim is that culture makes particular elements salient in the Interpretant of the target domain such that, when speakers construct a metaphor, they choose a source domain which contains in its Interpretant some of the salient elements of the Interpretant of the target domain. Thus, Quinn claims that, when using a metaphor, "the speaker has the reasoning he wants to do in mind independently of the metaphors in which he casts it" $3(87)$. To illustrate this claim, Quinn uses the 'American cultural model of marriage' as an example. When

\footnotetext{
${ }^{3}$ It may seem, initially, that Quinn's model is subject the same critique put forth by Ricoeur of Aristotle. Namely, that it is not the case that metaphor merely represents information already present. To argue that this critique is not applicable to Quinn's model, I draw your attention to the focus of Quinn's model: understanding. While Aristotle's theory of metaphor concerns the Object of the sign relation, Quinn's theory, like Ricoeur's, concerns the Interpretant (note the language "in the mind"). Quinn's claim is that there exists particular elements in the Interpretant that culture makes salient, and these salient elements suggest relationships of similarity to other Interpretants. To say that these relationships exist and that they are salient to interpreters is not to say, however, that the Representamen draws attention to these relationships. A metaphor thus provides "new information" to the interpreter in the sense that it draws attention to the already culturally salient relationships.
} 


\section{Cognitive Linguists:}

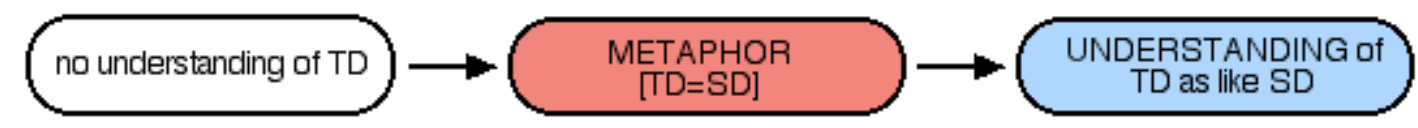

Quinn:

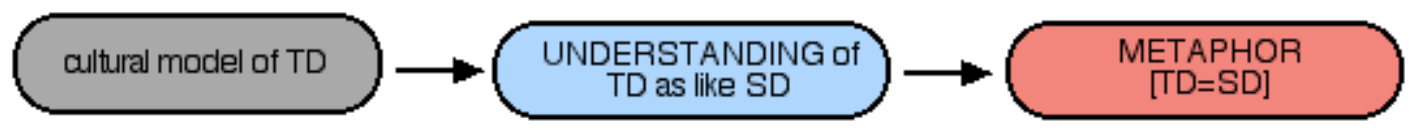

Figure 3.4: A comparative representation of Quinn's theory of metaphor and that of cognitive linguists, where TD denotes target domain and SD denotes source domain.

discussing marriage, the "reasoning" that the speaker has in mind is the cultural understanding of marriage. Quinn suggests that "sharedness, lastingness, and effort" are part of the American cultural model of marriage (78). These are the elements that 'American culture' makes salient in Interpretants of marriage. To capture this cultural understanding, that is, these elements of marriage, the speaker constructs a metaphor by selecting a source domain that shares these elements. For example, a speaker may use the metaphor that marriage (target domain) is an "ongoing journey" (source domain). In such a metaphor, the speaker might say "We're sort of tied together, you know, like a three-legged race" (78). It should be noted that although Quinn, like the cognitive linguists, frames her model in terms of the 'construction' of the metaphor, the same principles apply to interpretation. That is, a speaker who is a member of 'American culture' will interpret the metaphor "We're sort of tied together, you know, like a three-legged race," by identifying certain elements in the Interpretants of the target and source domains. The speaker will be drawn to the elements suggested by culture. In Quinn's view, then, cultural knowledge is not independent of metaphor, as cognitive linguists suggest, but rather integral to both its construction and interpretation.

Fig. 3.4 is a comparative representation of the two models. I use the term UN- 
DERSTANDING in the figure to denote the recognition of a relationship of similarity between two Interpretants. The model posited by the cognitive linguists may be roughly represented by two logical stages: (i) the construction of the metaphor and (ii) the understanding produced by the metaphor. In the first stage, the speaker, motivated by a failure to understand a target domain, constructs a metaphor using a more basic idea as a source domain. As a result of this metaphor, the speaker has a novel understanding of the target domain. Quinn's model, in contrast, contains three stages: (i) culture, (ii) understanding, and (iii) metaphor. In the first stage, the speaker's culture suggests a conception of the target domain; that is, the speaker's culture makes particular elements within the Interpretant of the target domain salient. This conception entails the recognition, or understanding, of the relationship between the target Interpretant and other Interpretants that have the culturally salient elements as their primary elements. In a logical sense, it may be too strong to claim that culture entails understanding, but there is nonetheless a very strong sense in which culture suggests relationships of similarity to other Interpretants. The second stage, thus, is the understanding of the target domain as like the source domain. In the third stage, speakers produce a metaphor that reflects this understanding. Thus, the critical difference between the two theories is the source of understanding: For cognitive linguists it is the metaphor, while for Quinn it is culture.

Interestingly, though they fail to identify it as metaphor, some cognitive psychologists frame the notion of categorization in terms very similar to Peirce (as presented in Section 3.1.1). In presenting a theory of mental categories, Daniel Reisberg suggests that categorization is a product of "a judgement based simply on the resemblance between [...] conceptual information" (305). Consider the following paragraph, from the chapter on "Concepts and Generic Knowledge" in his introductory cognitive psychology text:

If, therefore, we want to explain resemblance in terms of shared proper- 
ties, we're going to need some further theory to explain how we choose which properties to include when making the comparison. As a more extreme demonstration of this point, consider plums and lawn mowers. How similar are these to each other? Actually, these two have many properties in common: Both weigh less than a ton, both are found on Earth, both cannot hear well, both have an odor, both are used by people, both can be dropped, both cost less than a thousand dollars, both are bigger than a grain of sand, and so on. Of course, we ignore most of these shared features in judging these two entities, and so, as a result, we regard plums and lawn mowers as rather different from each other. But that brings us back to a familiar question: How do we decide which features to ignore when assessing similarity, and which features to consider? How do we decide, in comparing a plum and a lawn mower, which of their features are essential (and so do matter for similarity) and which are superficial (an can be ignored)? (Reisberg 311)

For Reisberg, Peircean elements are "shared properties" and the identity of one or more of those elements is "resemblance" of concepts. The "further theory" which cognitive psychologists propose to answer the question of "how we decide which features to ignore when assessing similarity, and which features to consider" is the notion of PSYCHOLOGICAL ESSENTIALISM. Psychological essentialism is the idea that all human beings share a common understanding about how the world works, and it is this understanding that motivates how we decide the relevant features in categorization (Medin and Ortony). The "relevant features," for cognitive psychologists, thus, are "essences." Quinn begins her proposal with the same question presented by Reisberg. However, her solution, her "further theory" to solve this question, is the point of divergence from cognitive psychologists. She answers this question by suggesting that it is culture, rather than psychological essentialism, that motivates the selection of the relevant features in categorization. Thus, Quinn "retakes" metaphor from the cognitive semanticists, and in doing so, she also provides an alternate theory to their concern of mental categories.

In light of Friedrich's emphasis on the individual's imagination, however, it seems unlikely that cultural knowledge could account for all metaphors in poetic language. 
It seems far more plausible that both theories are partially correct. That is, some metaphors are constructed from the basis of a cultural understanding and some metaphors are constructed as a means to understand. I argue, however, that the former case describes the large majority of metaphors in poetic language; it is the exception rather than the rule that poetic metaphors are employed as a tool for understanding. As a theory about poetic metaphor in 'typical' discourse, thus, Quinn's claim that metaphor is grounded in cultural understanding becomes an important step toward the aim of relating Whorfian linguistic relativity to Silverstein's broader theory of culture.

Before making an explicit claim about the relationship between Whorfian linguistic relativity and Silverstein's theory of culture, it is necessary, first, to outline two critical assumptions. The first assumption is that Quinn's claim that metaphor is based in cultural knowledge applies to metaphors constructed both at and below the level of reference and predication. That is, that Quinn's claim applies to metaphor in poetic language as well as metaphorical interpretations of grammatical categories. Put another way, it is necessary to assume that Quinn's claim concerns metaphor in the Peircean sense, since it has been argued that both types of metaphor have Peircean characteristics of metaphor. The second assumption is not so much an assumption as a careful statement of what has thus far remained implicit: metaphor is the semiotic device at issue in the categorization of Interpretants; in conceptual categories. To understand this claim, consider the category of $<$ pet $>$, containing the elements $\langle$ cat $\rangle,\langle\operatorname{dog}\rangle,\langle f i s h\rangle$, and $<$ hamster $\rangle$. This category can be thought of metaphorically in the following fashion: A $<$ cat $>$ 'is' a $<\operatorname{dog}>$ 'is' a $<$ fish $>$ 'is' a $<$ hamster $>$. Each of these elements, as Interpretants, themselves contain many elements. There is one element that is identical in each of the Interpretants and it is on the basis of this element that the Interpretants $<$ cat $>,<\operatorname{dog}>,<$ fish $>$, and $<$ hamster $>$ are categorized together. An $<$ amoeba $>$ is not a member of the $<$ pet $>$ 
category because it does not contain this element in its Interpretant. That is, an $<$ amoeba $>$ 'is' not a $<$ cat $>$ or a $<\operatorname{dog}>$. Categories are thus the identification of an identical element in a set of Interpretants; that is, they are metaphorical interpretations. We can therefore speak of conceptual categories as being METAPHORICAL CLASSES.

By accepting these assumptions, it is a small step to relate Whorfian linguistic relativity to Silverstein's theory of culture: Whorfian theory, conceived of as metaphor, concerns the construction of stereotypic knowledge. A stereotype, as defined in Chapter II (pg. 38), is symbolic knowledge about an object in the world; a category. Stereotypes, along with knowledge schema, form a cultural concept. From the second assumption above, I conclude that stereotypes are metaphorical classes. Thus, the claim that speakers have limited awareness of their metaphorical interpretations of grammatical categories is to say, in part, that speakers have limited awareness of certain stereotypes. More broadly, it is to say that speakers have limited awareness of culture. Note, crucially, however, that my claim is not that metaphor, and thus the concern of Whorfian linguistic relativity, is identical to culture. Rather, I argue that metaphor concerns a particular element in Silverstein's theory, stereotypes, which are, in turn, embedded within a broader theory of culture (see Fig. 2.6). A view that metaphor concerns only part of culture is consistent with Quinn's view: Quinn states that "there is more to culture than just metaphor" (57).

Thus, the place of Whorfian linguistic relativity in Silverstein's theory of culture emerges. Culture makes particular elements salient in Interpretants. These salient elements become the criteria for classifying Interpretants as similar; for categorization. The classification of Interpretants as similar is metaphor. Within Silverstein's theory of culture, this classification of Interpretants is represented by stereotypes. Fashions of speaking, as culturally shared metaphorical interpretations, are part of culturespecifically, they partially constitute stereotypes. Speaker's unawareness of fashions of 
speaking has consequences for awareness of culture: speakers have limited awareness of culture. 


\section{Chapter 4}

\section{Conclusion}

My argument, as a whole, is summarized graphically in Fig. 4.1. The figure represents a parallel formulation of Whorfian and Neo-Whorfian linguistic relativity, as framed in terms of the principle of unavoidable referentiality. The $y$-axis represents the degree to which a chunk of meaning coincides with, or 'rides on,' a form with denotational value. The higher the value on the $y$-axis the more meaning and form coincide. The $x$-axis represents linguistic relativity in different domains of meaning. On the left, is linguistic relativity in the symbolic domain, or Whorfian linguistic relativity, and on the right is linguistic relativity in the indexical domain, or Neo-Whorfian linguistic relativity. In each domain of meaning, there are two points of interest along the $y$-axis: a low and a high value. In the Neo-Whorfian realm, the high point corresponds to the case of the mother-in-law style (pg. 30) in which each vocabulary item has a pragmatic meaning. The low point in the Neo-Whorfian realm corresponds to the case of the Native American language Kiksht (pg. 31) in which the augmentative and diminutive pragmatic forms do not coincide with a form with denotational value. In the Whorfian realm, the low point represents Whorf's central claim that there exists relativity in habitual thought (as presented in Chapter I). Crucially, it becomes possible to locate this point only by framing Whorf's claim in terms of Peircean metaphor (the aim 


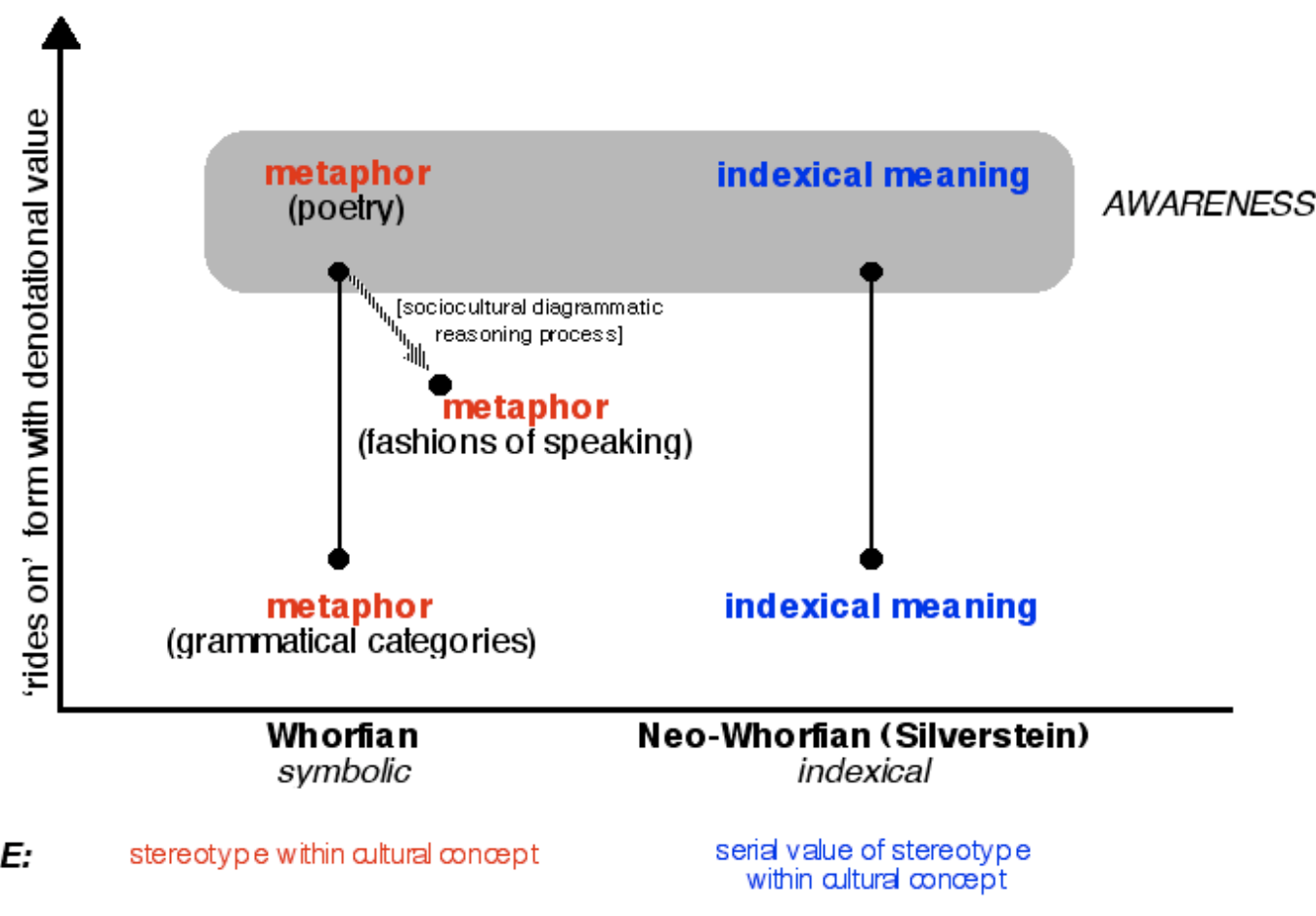

Figure 4.1: A parallel representation of Whorfian and Neo-Whorfian theory, as framed in terms of the principle of unavoidable referentiality.

of Chapter III). That is, the framing of Whorf's claim as metaphor allows Whorfian linguistic relativity to be 'placed' on the same axes as those of Neo-Whorfian linguistic relativity. I argue that the high point in Whorfian linguistic relativity, corresponding to that in the Neo-Whorfian domain, is poetic language (pg. 56). In the case of both domains, the high point exists above speakers' plane of awareness, and the low point exists below the plane of awareness. Fashions of speaking are the degenerate case of poetic language which have been demoted from the plane of awareness through the sociohistorical diagrammatic reasoning process. Finally, corresponding to these two domains of linguistic relativity are elements of Silverstein's theory of culture: Neo-Whorfian linguistic relativity corresponds to the awareness of the serial value of a stereotype within a cultural concept and Whorfian linguistic relativity corresponds to awareness of stereotypes, themselves. 


\section{Bibliography}

Boas, Franz. Introduction to Handbook of American Indian Languages. 1911. Lincoln, NE: University of Nebraska Press, 1966.

Carroll, Lewis. Hunting of the Snark and other Poems and Verses. New York: Harper \& Brothers, 1903.

Commens Dictionary of Peirce's Terms. eds. Mats Bergman and Sami Paavola. 2003. 20 March 2009. <http://www.helsinki.fi/science/commens/dictionary. html>.

Croft, William, and Alan D. Cruse. Cognitive Linguistics. Cognitive Textbooks in Linguistics. Cambridge: Cambridge University Press, 2004.

Crystal, David. An Encyclopedic Dictionary of Language and Languages. Oxford: Blackwell Publishers, 1992.

A Dictionary of Linguistics \& Phonetics. 5th ed. Oxford: Blackwell Publishers, 2003.

Ducrot, Oswald, and Tzvetan Todorov. Encyclopedic Dictionary of the Sciences of Language. trans. Catherine Porter. Baltimore: The Johns Hopkins University Press, 1979.

Foley, William A. Anthropological Linguistics: An Introduction. Malden, MA: Blackwell Publishers, 1997.

Friedrich, Paul. The Language Parallax. Austin: University of Austin Press, 1986.

—. "Polytropy." Beyond Metaphor: The Theory of Tropes in Anthropology. ed. James W. Fernandez. Stanford, CA: Stanford University Press, 1991.

Jappy, Tony. "Iconicity, Hypoiconicity." eds. João Queiroz and Ricardo Gudwin. 20 March 2009. <http://www.digitalpeirce.fee.unicamp.br/jappy/hypjap. $\mathrm{htm}>$.

Lucy, John A. Language Diversity and Thought: A Reformulation of the Linguistic Relativity Hypothesis. Cambridge: Cambridge University Press, 1992.

Matthews, Peter. A Short History of Structural Linguistics. Cambridge: Cambridge University Press, 2001. 
. The Concise Oxford Dictionary of Linguistics. Oxford University Press, 2007. Oxford Reference Online. Oxford University Press. 26 April 2009. <http://www . oxfordreference. com/views/ENTRY .html? subview=Main\&entry=t36. e3236>.

Medin, Douglas, and Andrew Ortony. "Psychological Essentialism." Similarity and Analogical Reasoning. eds. Stella Vosniadou and Andrew Ortony. Cambridge: Cambridge University Press, 1989.

Melville, Herman. Moby-Dick, or, The Whale. New York: The Modern Library, 2000.

Paulsen, Aurora. "Resurrecting the Dead: Revisiting Benjamin Lee Whorf's Principle of Linguistic Relativity." Undergraduate thesis. Reed College, 2008.

Peirce, Charles Sanders. The Collected Papers of Charles Sanders Peirce. 1931-1958. vols. 1-6, eds. Charles Hartshorne and Paul Weiss, vols. 7-8, ed. Arthur W. Burks. Cambridge, MA: Harvard University Press, 1960.

- The Essential Peirce: Selected Philosophical Writings. Vol. 2 (1893-1913), ed. The Peirce Edition Project. Bloomington, IA: Indiana University Press, 1998.

Quinn, Naomi. "The Cultural Basis of Metaphor." Beyond Metaphor: The Theory of Tropes in Anthropology. ed. James W. Fernandez. Stanford, CA: Stanford University Press, 1991.

Reisberg, Daniel. Cognition: Exploring the Science of the Mind. 3rd. ed. New York: W.W. Norton, 2006.

Richards, I.A. The Philosophy of Rhetoric. New York: Oxford University Press, 1936.

Ricœur, Paul. The Rule of Metaphor: Multidisciplinary Studies of the Creation of Meaning in Language. trans. Robert Czerny. Toronto: University of Toronto Press, 1977.

Sapir, Edward. Language: An Introduction to the Study of Speech. San Diego: Hartcourt Brace Jovanovich, 1949.

Saussure, Ferdinand. Course in General Linguistics. eds. Charles Bally, Albert Sechehaye and Albert Riedlinger. trans. Roy Harris. Chicago: Open Court, 1986.

Shakespeare, William. As You Like It. ed. Stanley Wells. Oxford: Oxford University Press, 1998.

2006.

Silverstein, Michael. "Language and the Culture of Gender: At the Intersection of Structure, Usage and Ideology." Semiotic Mediation. eds. Elizabeth Mertz and Richard. J. Parmentier. Orlando, FL: Academic Press, 1985. 
. "Whorfianism and the Linguistic Imagination of Nationality." Regimes of Language: Ideologies, Polities, and Identities. ed. Paul V. Kroskrity. Santa Fe, NM: School of American Research Press, 2000.

—. "The Limits of Awareness." Linguistic Anthropology: A Reader. ed. Alessandro Duranti. Blackwell Anthologies in Social and Cultural Anthropology 1. Malden, MA: Blackwell Publishing, 2001.

. "Indexical Orders and the Dialectics of Sociolinguistic Life." Language and Communication 23 (2003): 193-229.

_. "Cultural" Concepts and the Language-Culture Nexus." Current Anthropology 5.4 (December 2004): 621-652.

Stjernfelt, Frederik. Diagrammatology: An Investigation on the Borderlines of Phenomenology, Ontology, and Semiotics. Dordrecht: Springer, 2007.

Whorf, Benjamin Lee. Language, Thought, and Reality: Selected Writings of Benjamin Lee Whorf. ed. John B. Carroll. Cambridge, MA: The Massachusetts Institute of Technology Press, 1956. 